\title{
Dantu's mineralogical properties - A view into the composition of Ceres' crust
}

\author{
K. STEPHAN (D ${ }^{1, *}$, R. JAUMANN ${ }^{1,2}$, R. WAGNER ${ }^{1}$, M. C. DESANCTIS (D ${ }^{3}$, E. PALOMBA ${ }^{3}$,

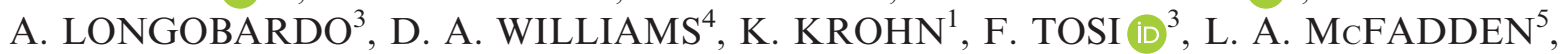 \\ F. G. CARROZZO ${ }^{3}$, F. ZAMBON ${ }^{3}$, E. AMMANNITO ${ }^{6}$, J.-P. COMBE ${ }^{7}$, K.-D. MATZ ${ }^{1}$, \\ F. SCHULZECK ${ }^{1}$, I. vON DER GATHEN ${ }^{1}$, T. ROATSCH ${ }^{1}$, C. A. RAYMOND ${ }^{8}$, and C. T. RUSSELL ${ }^{6}$ \\ ${ }^{1}$ DLR, Institute of Planetary Research, Berlin, Germany \\ ${ }^{2}$ Free University of Berlin, Berlin, Germany \\ ${ }^{3}$ INAF-IAPS, Rome, Italy \\ ${ }^{4}$ Arizona State University, Tempe, Arizona 85287, USA \\ ${ }^{5}$ NASA Goddard Space Flight Center, Greenbelt, Maryland 20771, USA \\ ${ }^{6}$ Institute of Geophysics and Planetary Physics, UCLA, Los Angeles, California 90095, USA \\ ${ }^{7}$ Bear Fight Institute, Winthrop, Washington 98862, USA \\ ${ }^{8}$ NASA-JPL Pasadena, Pasadena, California 91109, USA \\ *Corresponding author. E-mail: katrin.stephan@dlr.de
}

(Received 01 June 2017; revision accepted 12 May 2018)

\begin{abstract}
Impact crater Dantu not only exhibits a very complex geological history but also shows an exceptional heterogeneity of its surface composition. Because of its location within a low-lying region named Vendimia Planitia, which has been proposed to represent an ancient impact basin, Dantu possibly offers a window into the composition of Ceres's deeper crust, which apparently is enriched in ammonia. Local concentration of carbonates within Dantu or its ejecta blanket may be either exposed or their emplacement induced by the Dantu impact event. Because carbonates can be seen along Dantu's crater walls, exposed due to recent slumping, but also as fresh spots or clusters of spots scattered across the surface, the deposition/formation of carbonates took place over a long time period. The association of several bright spots enriched in carbonates with sets of fractures on Dantu's floor might be accidental. Nevertheless, its morphological and compositional similarity to the faculae in Ceres's prominent impact crater Occator including its hydrated state does not exclude a cryo-volcanic origin, i.e., upwelling of carbonate-enriched brines influenced by $\mathrm{H}_{2} \mathrm{O}$ ice in the subsurface. Indeed, an isolated $\mathrm{H}_{2} \mathrm{O}$ ice spot can be identified near Dantu, which shows that ice still exists in Ceres's subsurface at midlatitudes and that it can exist on the surface for a longer period of time.
\end{abstract}

\section{INTRODUCTION}

In 2001, NASA decided to select a low-cost mission named Dawn to investigate bodies in the asteroid belt, which are thought to be representatives from the dawn of planetary evolution in the early solar system (Russell and Raymond 2011). Dawn is the first planetary mission to visit two objects in the main asteroid belt with a single spacecraft, asteroid (4) Vesta and dwarf planet (1) Ceres. From July 2011 to September 2012, Dawn successfully carried out detailed investigations of (4) Vesta from orbit (Russell et al. 2012). On March 6,
2015, the Dawn spacecraft was inserted into a polar orbit around (1) Ceres and started to study the largest body in the asteroid belt (Russell et al. 2016).

Since NASA's Dawn spacecraft arrived at Ceres in March 2015, it has shown that the surface composition of the dwarf planet Ceres is dominated by a mixture of ammoniated phyllosilicates, Mg-phyllosilicates, carbonates, and a spectrally featureless visually dark material (De Sanctis et al. 2015). This composition has been found to be rather homogeneous on a global scale, implying a globally widespread endogenous formation of the surface material, i.e., an aqueous alteration of silicates (Ammannito et al. 
2016b). The abundance and/or physical properties of the individual surface compounds, however, appear to be quite variable on a regional and local scale, which could be evidence of a vertically stratified upper crust (Ammannito et al. 2016b) or could result from specific surface processes (Stephan et al. 2017a). Local enrichment of carbonates could be identified in numerous places on Ceres with the most prominent locality in Occator crater composed of Nabearing carbonates (De Sanctis et al. 2016; Longobardo et al. 2017b; Carrozzo et al. 2018). Postimpact processes as well as cryo-volcanism can be responsible for the existence of carbonates on Ceres. Dawn's Gamma Ray and Neutron Detector (GRaND) infers $\mathrm{H}_{2} \mathrm{O}$ ice to be ubiquitous in Ceres's subsurface (Prettyman et al. 2017). Indeed, the visible and infrared spectrometer (VIR) identified several places of exposed $\mathrm{H}_{2} \mathrm{O}$ ice predominantly located close to the polar regions (Combe et al. 2016), where it is expected to be relatively stable (Hayne and Aharonson 2015). Finally, local deposits of organic material were discovered on the surface (De Sanctis et al. 2017).

In this work, we explore the composition of one of Ceres's complex surface features, the impact crater Dantu, which in a geological sense appears to be an older version of Ceres's prominent impact crater Occator. Nevertheless, Dantu is still young enough that a wide variety of intercrater features are recognizable, providing insight into the impact process. Furthermore, Dantu lies in one of Ceres's presumed ancient impact basins (Marchi et al. 2016; Williams et al. 2017) and thus is expected to excavate material from deep within Ceres's crust. Dantu has been spectrally investigated in general during the compositional mapping campaign by the Dawn team. However, Dantu itself crosses multiple quadrangles, each covering only a part of the crater, and its spectral properties has been analyzed only in pieces (Carrozzo et al. 2017; Palomba et al. 2017a; Stephan et al. 2017b) preventing a thorough interpretation of its geochemical evolution and drawing clues for the geochemical evolution of the entire body. In this work, we look at the entire impact feature. This investigation offers the opportunity to further our understanding about the compositional and geological evolution of Ceres's crust as well as details of local geochemical processes.

\section{DATABASES AND METHODOLOGY}

The Dawn mission at Ceres consists of three principal phases performed at different altitudes of the spacecraft from the surface in order to maximize coverage and to meet the viewing conditions of the requirements of mapping Ceres's surface: the Survey Orbit (altitude of $\sim 4430 \mathrm{~km}$ ), the High Altitude Mapping Orbit (HAMO, altitude of $\sim 1475 \mathrm{~km}$ ), and Low Altitude Mapping Orbit (LAMO) (altitude of $\sim 375 \mathrm{~km}$ ) (Russell et al. 2016). These phases were part of the Nominal or Prime Mission at Ceres. In the Dawn Extended Mission, three orbital phases were added: (d) the Extended Mission Orbit 1 (XMO1), an extension of the LAMO orbit ( $\sim 385 \mathrm{~km}$ altitude); (e) XMO2, an orbit comparable to HAMO ( 1500 km); and XMO3 ( 7200 km altitude). In order to investigate the composition of Ceres's surface in detail, we mainly used images of Dawn's framing camera (FC) and hyperspectral VIR cubes acquired during the Survey, HAMO, and LAMO mission phase, with the latter offering the highest pixel ground resolution possible in the entire Dawn mission.

\section{VIR Observations}

The VIR instrument detects Ceres's surface between 0.25 and $1.05 \mu \mathrm{m}$ (VIS) and between 1.0 and $5.1 \mu \mathrm{m}$ (IR) (De Sanctis et al. 2011). VIR data have been radiometrically calibrated by the VIR team following the procedure of Filacchione et al. (2011) and instrument-dependent artifacts in the VIR spectra have been removed using the methods described by Carrozzo et al. (2016). In order to study the spectral characteristics of Ceres's spectra at wavelengths longer than $3 \mu \mathrm{m}$, which are strongly affected by Ceres's thermal signal, a correction of the thermal signal has been performed as described in Raponi (2015). The average spatial resolution of VIR hyperspectral images ("cubes") is as good as $380 \mathrm{~m}$ per pixel during HAMO and $95 \mathrm{~m}$ per pixel during LAMO enabling mapping spatial variations in Ceres's surface composition on a regional and local scale. The average spectral sampling is $1.8 \mathrm{~nm}$ (VIS) and $9.8 \mathrm{~nm}$ (IR) per spectral channel, which allows the identification of major surface compounds and mapping the distribution of their diagnostic absorptions. Variations in the spectral parameters of these absorptions, i.e., their spectral parameters such as the band center (BC) and the band depth (BD) may depend on the abundance and on the physical properties (in particular, the grain size) of the specific surface compound. Detailed mapping of these variations enables the investigation of Ceres's surface composition depending on its location on the body as well as on the surface geology and topography, which is essential to reveal their origin and surface processes responsible for their existence. Measurements of the $\mathrm{BCs}$ and $\mathrm{BDs}$ of individual absorptions have been performed following the procedure of Clark (2003), as described in detail by Ammannito et al. (2016a).

\section{FC Images and FC-Derived Data Sets}

Images from the Framing Camera, which offer the geological context of the Dantu region, reach spatial 


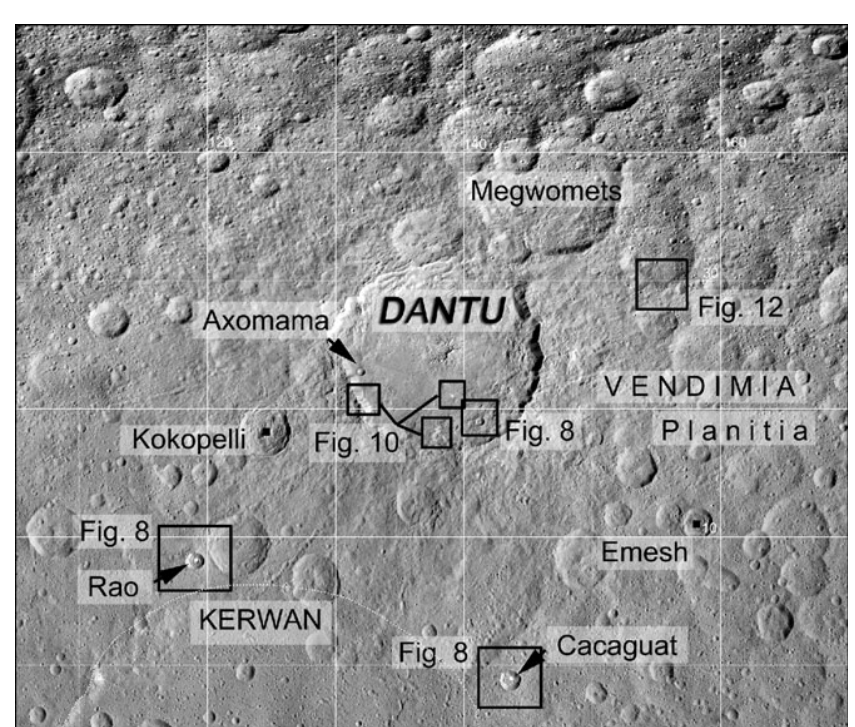

Fig. 1. Geological context of impact crater Dantu in a FC Clear filter LAMO mosaic. Black boxes outline areas that appear in later figures.

resolutions up to $\sim 140 \mathrm{~m} /$ pixel (HAMO) and $\sim 35 \mathrm{~m} /$ pixel (LAMO). In order to study the relationship between surface composition and geology in general, a LAMO mosaic with a mean resolution of $35 \mathrm{~m}$ per pixel (Roatsch et al. 2016) has been used (Fig. 1). The comparison of local spectral changes and geology was done using individual FC images acquired during the LAMO phase, preferentially acquired at a similar time of day as the corresponding VIR observation and thus with similar illumination conditions.

FC data, however, do not only offer the geologic context for our spectral investigation but also provide spectral information from its seven color filters, which are sensitive in a wavelength range between 0.4 and $1.1 \mu \mathrm{m}$ (Sierks et al. 2011). For each filter, a global photometrically corrected HAMO mosaic is available (Schröder et al. 2013; Roatsch et al. 2016). Although these images do not offer a continuous spectrum like the VIR observations, they are useful to see changes in the visible albedo and spectral slope at a much higher spatial resolution-revealing correlations between composition and geology at a local scale.

\section{GEOLOGY OF DANTU CRATER AND ITS SURROUNDINGS}

\section{Location of the Study Area and Geologic Context}

Figure 1 shows the studied area located between $5^{\circ} \mathrm{S}$ and $50^{\circ} \mathrm{N}$ and 105 and $170^{\circ} \mathrm{E}$, as observed in $\mathrm{FC}$ LAMO images at a spatial resolution of $35 \mathrm{~m}$ per pixel. The $126 \mathrm{~km}$ large complex crater Dantu centered at $24.3^{\circ} \mathrm{N}$ and $138.23^{\circ} \mathrm{E}$ and its surroundings are mainly dominated by heavily cratered terrain with numerous prominent impact craters. In the cartographic maps of Ceres (Roatsch et al. 2016), the area shown in Fig. 1 is placed within three HAMO quadrangles: Ac-H 3 (Dantu), Ac-H 7 (Kerwan), and Ac-H 8 (Nawish). HAMO-based geologic maps of these three quadrangles were provided by Kneissl et al. (2016), Williams et al. (2017), and Frigeri et al. (2016), respectively.

One of the old degraded impact craters in the direct neighborhood of Dantu is Megwomets, a $78.7 \mathrm{~km}$ large slightly irregularly shaped impact crater located northeast of Dantu and near contiguous with Dantu at $36.5^{\circ} \mathrm{N}$ and $146.2^{\circ} \mathrm{E}$. The nearest large impact structure, which has been determined to be the oldest large impact crater on Ceres (Williams et al. 2017), is Kerwan to the southwest, $284 \mathrm{~km}$ in diameter, centered at $10.8^{\circ} \mathrm{S}$ and $124.0^{\circ} \mathrm{E}$ (northern rim dotted in Fig. 1). Both Dantu and Kerwan are superimposed on an approximately circular and topographically low-lying area termed Vendimia Planitia. This area extends from $65^{\circ} \mathrm{N}$ to $20^{\circ} \mathrm{S}$ and from $85^{\circ} \mathrm{E}$ to $185^{\circ} \mathrm{E}$ as inferred from Dawn FC stereo data (Preusker et al. 2016; Roatsch et al. 2016) and is interpreted to represent an old, $\sim 800 \mathrm{~km}$ large heavily degraded impact basin (Marchi et al. 2016). Based on the cratering chronology models discussed in Hiesinger et al. (2016) by which absolute model ages (AMAs) can be derived from crater counts on geologic units of Ceres, Dantu formed $72-150 \mathrm{Ma}$ ago (lunarderived model, LDM), or 43-94 Ma ago (asteroidderived model, ADM) (Williams et al. 2017). In contrast, the Kerwan impact event took place approximately $1.3 \mathrm{Ga}$ ago in the lunar-derived model (LDM) versus $280 \mathrm{Ma}$ in the ADM. Northward of Dantu, the interior of the presumed basin is represented by a hummocky, densely cratered unit mapped as cratered terrain (crt) by Kneissl et al. (2016). Southward, especially around the large crater Kerwan, the terrain is smoother instead and was mapped as smooth material (Frigeri et al. 2016; Williams et al. 2017).

Centeotl, a $6 \mathrm{~km}$ large impact crater, is superimposed on the southeastern crater floor of Dantu $\left(18.9^{\circ} \mathrm{N} / 141.2^{\circ} \mathrm{E}\right)$. The slightly smaller $(\sim 5 \mathrm{~km})$ crater Axomama is located on the southwestern part of the floor $\left(22.8^{\circ} / 131.9^{\circ} \mathrm{E}\right)$. Absolute model ages (AMAs) for Axomama are $39 \pm 5 \mathrm{Ma}$ (LDM) versus $44 \pm 5 \mathrm{Ma}$ (ADM) (Wagner et al. 2017). AMAs of Centeotl are $1.8 \pm 0.7 \mathrm{Ma}$ (LDM) or $2.4 \pm 1.0 \mathrm{Ma}$ (ADM) (Wagner et al. 2017). The AMAs of both craters confirm their post-Dantu formation time.

Kokopelli, a $32.9 \mathrm{~km}$ crater, superimposes Dantu's continuous ejecta $\left(18.2^{\circ} \mathrm{N} / 124.5^{\circ} \mathrm{E}\right)$ and was most likely formed after Dantu (Fig. 1). The crater is characterized 
by an unusual morphology of its interior. It lacks a smooth or hummocky floor; instead terraces extend toward the center dominated by a broad central peak with a comparably flat summit region. Outside its rim to the northwest, numerous clusters of secondary craters are abundant.

Smaller pristine-looking and therefore also stratigraphically young craters near Dantu are Cacaguat (diameter: $13.6 \mathrm{~km}$, located at $1.2^{\circ} \mathrm{S} / 143.6^{\circ} \mathrm{E}$ ), Rao (diameter: $12 \mathrm{~km}$, located at $8.1^{\circ} \mathrm{N} / 119.0^{\circ} \mathrm{E}$ ), and Emesh (diameter: $20 \mathrm{~km}$, located at $11.1^{\circ} / 158.2^{\circ} \mathrm{E}$ ). These impact features are superimposed on the outer fringes of Dantu's ejecta to the southwest, south, and southeast, which like Dantu may lie within the region of Vendimia Planitia. Rao and Cacaguat are bright rayed craters (Williams et al. 2017) with comparable AMAs of $\sim 33 \mathrm{Ma}$ and $\sim 3.3 \mathrm{Ma}$, respectively (both LDM and ADM, Williams et al. 2017).

\section{Detailed Geology of Dantu}

Figure 2 shows the geologic map of Dantu produced by Kneissl et al. (2016) illustrating the highly complex morphology of Dantu crater. It is surrounded by an ejecta blanket extending approximately one to one and a half crater diameters outward from the rim. The ejecta blanket was mapped as one unit and termed crater material (c) (Kneissl et al. 2016). The ejecta materials have covered most of the pre-existing small and midsized crater population, indicated by the map signature buried impact crater rim. These superposition relationships imply that Dantu is a stratigraphically young large crater. Parts of the crater ejecta are covered by mantling material with gradational boundaries toward the unmantled areas (Kneissl et al. 2016). The mantling materials are dark south and southwest of Dantu, and bright north-, east-, and westward.

Chains of secondary craters extend radially away from Dantu, especially west- and southwestward, and overlap the northern rim of Kerwan. Approximately east-west-trending crater chains north of Dantu, e.g., those superimposing the rim of crater Megwomets, are believed to be secondaries that originate from material ejected in the Urvara or Yalode impact events (Schmedemann et al. 2017). Kneissl et al. (2016) mapped secondary crater chains, regardless of their source crater, as impact crater chains or collapsed lava tube (fine line signature).

In its interior, Dantu shows highly complex morphologic and geologic features mapped as separate units by Kneissl et al. (2016). Dantu features a rimmed and irregularly shaped central pitted terrain that opens to the west, probably representing the remnants of a collapsed central peak (unit ccp). The areas close to the inner rim are characterized by hummocky material, a unit mapped as hummocky crater floor material (cfh). Concentric inward-facing scarps, preferentially at Dantu's northern wall associated with slumping features and ridge crests are abundant within this unit and most likely represent wall terraces.

The major part of the floor appears more or less smooth to slightly hummocky, even at LAMO resolution. Kneissl et al. (2016) separated three different units: crater floor material (cf), bright crater floor material (cfb), and dark crater floor material (cfd). The latter occurs only near the southwestern wall, instead of hummocky crater floor material (cfh). Most of the floor consists of units $\mathrm{cfb}$ and $\mathrm{cf}$, with the latter covering a significant portion of the southwestern and southern floor. The southern part of Dantu's floor is also characterized by systems of linear to arcuate fractures overlying units $\mathrm{cfb}$ and $\mathrm{cf}$ which trend concentrically and radially with respect to the center of Dantu crater. Minor fractures extend radially outward from the central peak/pit complex toward the north. The entire crater floor, independent of the geologic unit, features many small craters, quite a few in clusters or chains, presumably secondary craters from outside Dantu. Clusters of pits near the limit of spatial resolution are scattered across the floor and could be endogenic features of nonimpact origin. These features are preferentially found within the central peak/pit complex.

Numerous local bright spots are scattered on Dantu's floor as well as outside Dantu. Although these spots appear everywhere, most of them are concentrated in the southern portion of the studied area. The VIRbased analysis by Palomba et al. (2016a) has revealed six bright spots in the area. They appear as bright streaks along the crater wall of Dantu or are associated with small craters, but mostly appear as local spots within Dantu's ejecta blanket. It is not clear if these spots are connected to the impact event of Dantu. Only one spot is located in the vicinity of the fractures on Dantu's floor, which may be accidental and does not provide evidence for any venting process. Possibly, they represent ejecta material originating from Kokopelli, the large crater southwest of Dantu (Fig. 1).

\section{DISTRIBUTION OF COMPOSITIONAL COMPONENTS AT DANTU}

Figure 3 shows the FC mosaic of photometrically corrected images centered at $550 \mathrm{~nm}$ and the enhanced true color mosaic combining the mosaics of FC images showing Ceres at 965, 550, and $438 \mathrm{~nm}$. The albedo of Dantu at $550 \mathrm{~nm}$ generally varies between $\sim 3 \%$ and $\sim 10 \%$ and only locally also exceeds $20 \%$ (see below), pointing to a high spectral heterogeneity on a local 


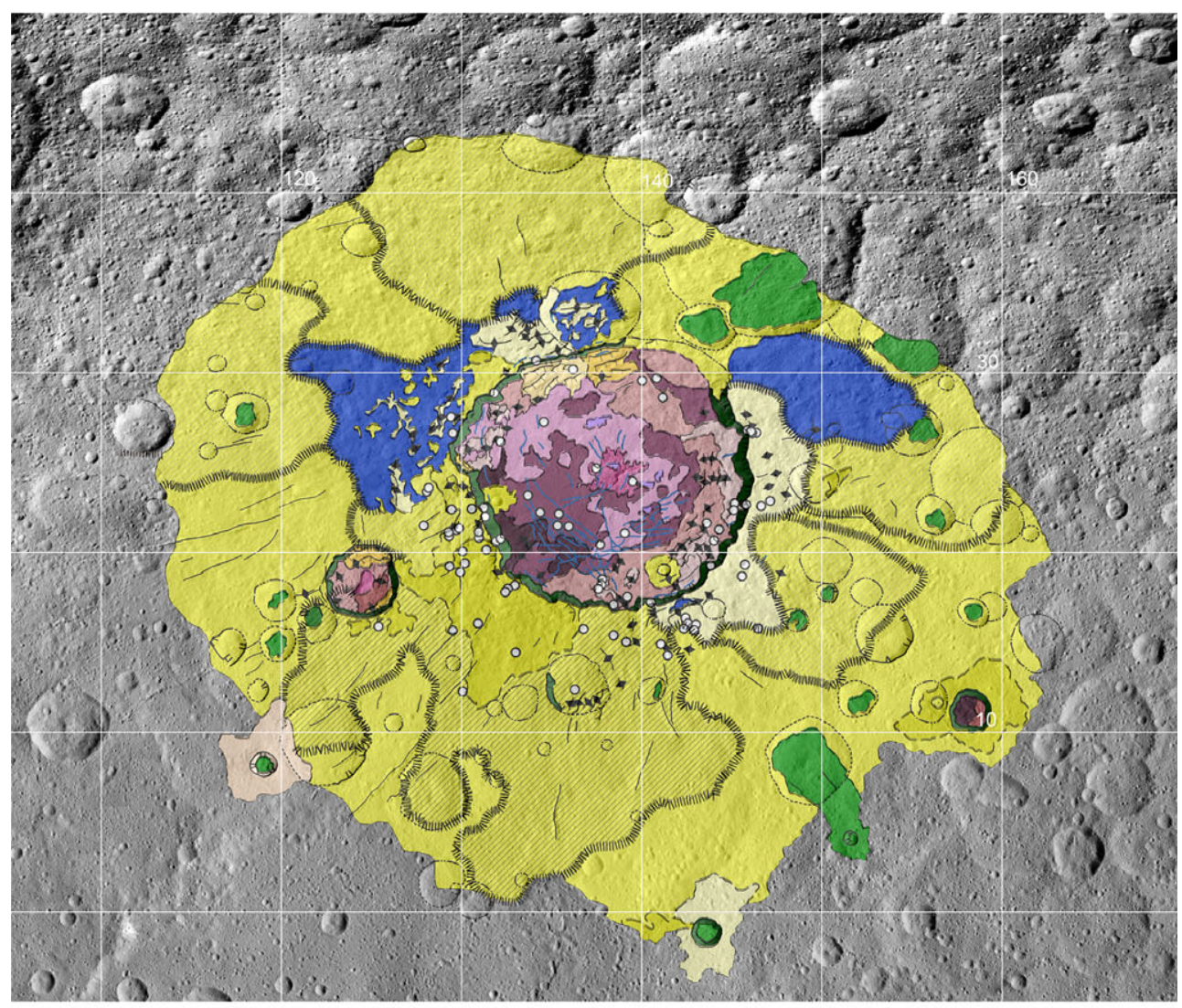

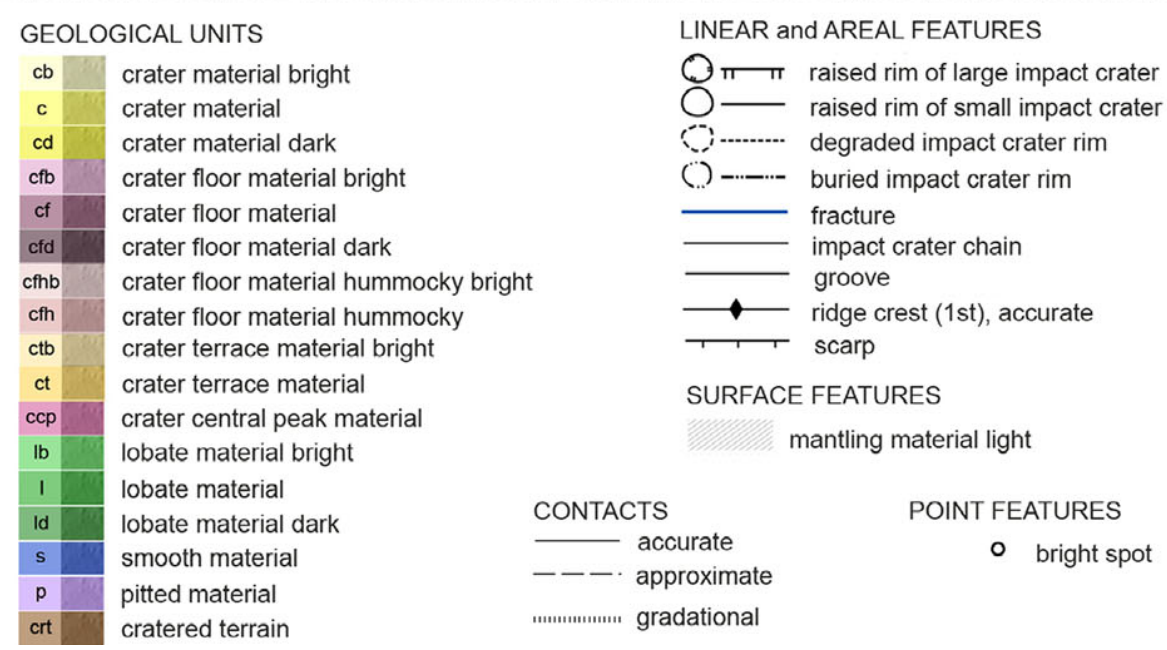

Fig. 2. Geological map of Dantu based on LAMO FC images (Fig. 1) adapted from Kneissl et al. (2016) and Williams et al. (2017). The borders of the geological units shown here are overlaid on the maps of Figs. 3, 4, 6, 7, and 9.

scale. The brightest areas include major parts of Dantu and its ejecta. Only the southwestern portion of the crater floor and the ejecta blanket exhibits a relatively low albedo and a bluish taint in the true color mosaic. Intriguingly, similar characteristics can be recognized in the vicinity of few pristine impact craters outside Dantu. Although impact crater Rao exhibits a relatively high albedo similar to Dantu's central parts, the impact craters Cacaguat and Emish exhibit a relatively low albedo such as seen in Dantu's southwestern portion.

These albedo variations also correspond to considerable variations in the color composite combining the ratio of images at 550,438, and $750 \mathrm{~nm}$ as well as the classification map of the ratio of images 

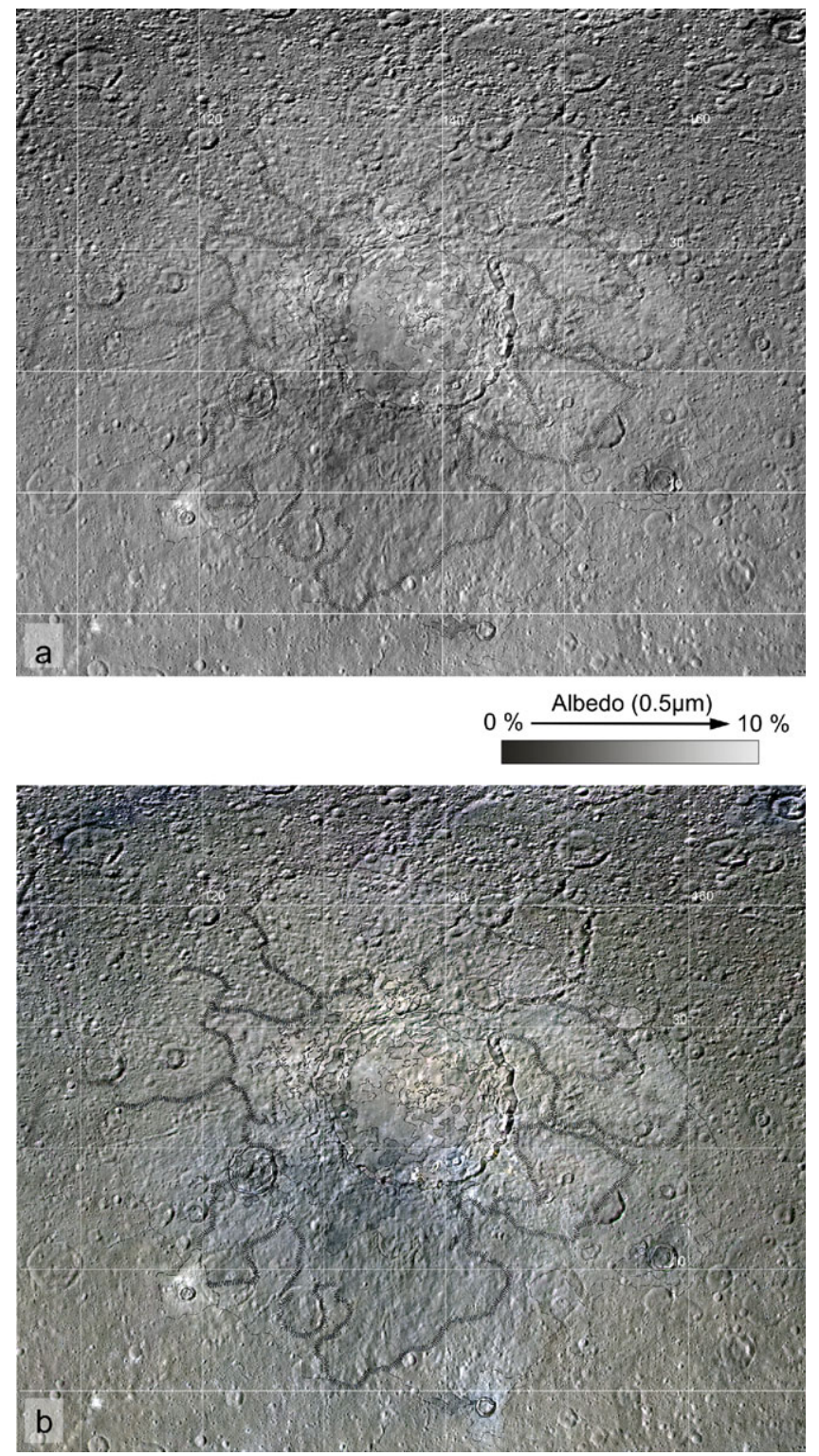

Fig. 3. FC-derived mosaics of impact crater Dantu: (a) normal albedo at $550 \mathrm{~nm}$, (b) true color mosaic using photometrically corrected FC images sensitive at 965, 550, and $438 \mathrm{~nm}$ in RGB, respectively.

at 438 and $750 \mathrm{~nm}$ indicating variations in the spectral slope as demonstrated in Stephan et al. (2017a) (Fig. 4). The bluish taint of the low albedo regions is strongly enhanced and appears in blue to violet colors. Intriguingly, Centeotl and Cacaguat, in contrast to the brighter Rao, are also characterized by bluish colors and a distinct negative blue (ratio $>1$ ) spectral slope. Despite the high albedo of Rao, its spectral slope does not significantly differ from its surroundings, whereas the northeastern portions of Dantu with the relatively high visible albedo show a more positive reddish (ratio
$<1)$ to neutral spectral slope with the reddest slope confined to Dantu's central peak.

The strong spectral heterogeneity indicated by the FC color data is also mirrored in the variety and spatial distribution of spectral signatures identified and mapped in the Dantu area. VIR spectra exhibit spectral signatures of most of the minerals identified on Ceres's surface so far (1) $\mathrm{Mg}$ - and $\mathrm{NH}_{4}$-bearing phyllosilicates, (2) $\mathrm{Ca} / \mathrm{Mg}$ - and Na-carbonates, and (3) very likely $\mathrm{H}_{2} \mathrm{O}$ ice. These surface compounds and partly also their physical parameters including the surface temperature at the time of the corresponding VIR observation are unevenly distributed through the Dantu area and appear to be associated with specific geological or morphological surface features in the Dantu area and/or intercrater features of Dantu itself.

\section{Mg- and $\mathrm{NH}_{4}$-Phyllosilicates}

Phyllosilicates are the most ubiquitous mineral assemblage throughout the Dantu area. Phyllosilicates are known to be responsible for the absorption centered at $2.72 \mu \mathrm{m}$ indicative of $\mathrm{OH}^{-}$(Fig. 5), which appears in every VIR spectrum of the area and whose BC favors Mg-bearing phyllosilicates (De Sanctis et al. 2015; Ammannito et al. 2016b). The BD of the absorption varies considerably (15-30\%) supporting a pronounced heterogeneity in either the abundance or the grain size of the phyllosilicates. The appearance of the absorption at $\sim 2.7 \mu \mathrm{m}$ in the VIR spectra of the area of interest usually is accompanied by a broad absorption at $\sim 3.1 \mu \mathrm{m}$ indicative of $\mathrm{NH}_{4}$-bearing phyllosilicates, whose $\mathrm{BD}$ varies less than the $\mathrm{OH}$-absorption, but which still clearly ranges between 5 and $15 \%$ (Fig. 5). Intriguingly, distinctly separated areas of relatively strong as well as weak absorptions at 2.7 and $3.1 \mu \mathrm{m}$ in the phyllosilicate-dominated regions of Dantu can be distinguished (Stephan et al. 2017a).

\section{Spatial Variations in the $\mathrm{BDs}$ of the $\mathrm{OH}$-Absorption at $2.7 \mu \mathrm{m}$}

In general, the spatial variations in the BDs of the $\mathrm{OH}$-absorption at $2.7 \mu \mathrm{m}$ exhibits a similar trend as can be seen in the FC color ratio composite and the classification of the visible spectral slope (Fig. 4). The phyllosilicate absorption at $2.7 \mu \mathrm{m}$ is very deep in the northern portion of Dantu crater with the largest BD of $\sim 30 \%$ in the center of Dantu crater in the vicinity of its central peak (Fig. 2: geological unit ccp, Figs. 5 and 6a: spectrum \#1). Outside Dantu, only impact crater Rao and its ejecta (Figs. 5 and 8: spectrum \#2) southeast of Dantu exhibit relatively deep absorptions at 2.7 of $\sim 23 \%$ as well. In FC color images, these parts of Dantu show a high albedo (Fig. 3), a 

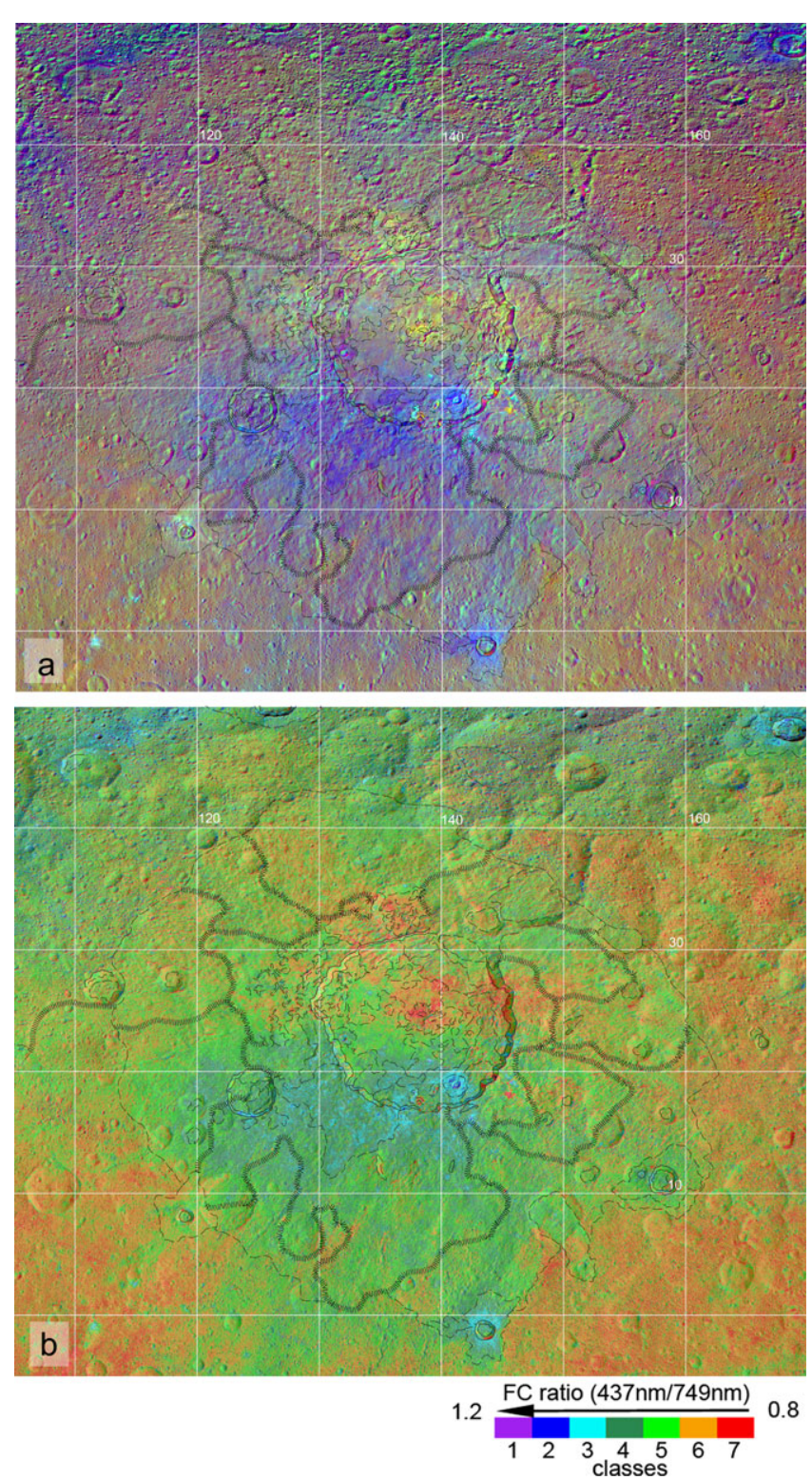

Fig. 4. FC derived color information of impact crater Dantu: (a) ratio color composite expressed as $\mathrm{RGB}$ with $\mathrm{R}=$ the ratio of images sensitive at 550 and $438 \mathrm{~nm}, \mathrm{G}=$ the image of the Dantu area at $550 \mathrm{~nm}$, and $\mathrm{B}=$ the ratio of images sensitive at 550 and $750 \mathrm{~nm}$; and (b) a classification of the ratio values derived from FC images sensitive at 438 and $750 \mathrm{~nm}$, respectively.

yellowish color in the color ratio composite and a more or less reddish spectral slope (Fig. 4). In contrast, the surface temperature of this area at the time of the VIR observation shows no difference to the surrounding regions (Fig. 7). Generally, surface temperatures follow the local topography, i.e., areas illuminated at large incidence angles are cooler (dark color) than areas illuminated at small incidence angles (bright color).
In contrast, regions with relatively weak absorptions at $2.7 \mu \mathrm{m}(\sim 17 \%)$ occur in the southern portion of Dantu crater itself and in Dantu's ejecta blanket (Fig. 2, geological unit c). These regions are either associated with the local bright spots (as indicated in the geological map of Fig. 2) or with the fresh impact crater Centeotl (Figs. 5 and 6a: spectrum \#4) on Dantu's crater floor and impact crater Cacaguat (Figs. 1 and 8). In contrast to the bright spots, which exhibit a concentration of carbonates (see the $\mathrm{Mg}$ - and $\mathrm{NH}_{4}$-Phyllosilicates section), the VIR spectra of Centeotl and Cacaguat are still dominated by phyllosilicates. The weak absorption at $\sim 2.7 \mu \mathrm{m}$, which dominates the crater floor and the ejecta of both impact features, is accompanied by a bluish spectral slope. This is evident in the vicinity of impact crater Centeol, the only surface feature that can also be distinguished by its relatively low surface temperature from the surroundings (Fig. 7). The bluish spectral slope dominates the entire crater and its ejecta, whereas along the southern crater wall of Cacaguat an increase of the BDs at 2.7 and a reddening of the visible spectral slope can be observed. Intriguingly, although the spectral properties of Centeotl and Rao significantly differ from each other, tiny impact craters located within Rao's ejecta blanket can be distinguished (indicated by a black arrow in Fig. 8), which apparently exhibit similar spectral properties as Centeotl. Even though the spatial resolution of the VIR data does not allow a sufficient characterization of the spectral properties of these tiny impact craters, Fig. 8 indicates a bluish FC-derived spectral slope and a slight decreasing in the $\mathrm{BD}$ of the absorption at $2.7 \mu \mathrm{m}$, which is possibly related to these impact features.

\section{Spatial Variations in the $\mathrm{BD}$ s of the $\mathrm{NH}_{4}$-Absorption at $3.1 \mu \mathrm{m}$}

Generally, most of the regions characterized by a deep absorption at $2.7 \mu \mathrm{m}$ also show a deep absorption at $3.1 \mu \mathrm{m}$, supporting the fact that ammoniated phyllosilicates are likely responsible for these variations (Ammannito et al. 2016b). The deepest absorption at $3.1 \mu \mathrm{m}$ has been measured in the vicinity of Dantu's central peak (Figs. 5 and 6b: spectrum \#1). Although impact Rao similar to Dantu's central peak also exhibits a relatively deep absorption at $2.7 \mu \mathrm{m}$ as well as $3.1 \mu \mathrm{m}(>10 \%)$, a relatively deep absorption at 3.1 $(>10 \%)$ can also be observed for impact crater Cacaguat, which otherwise exhibits a spectral signature unlike Rao but similar to impact crater Centeotl with a weak absorption at $2.7 \mu \mathrm{m}$ and a distinct bluish visible spectral slope (Fig. 8).

Thus, the association of the variations in the BDs of these two absorptions is not valid for the entire 

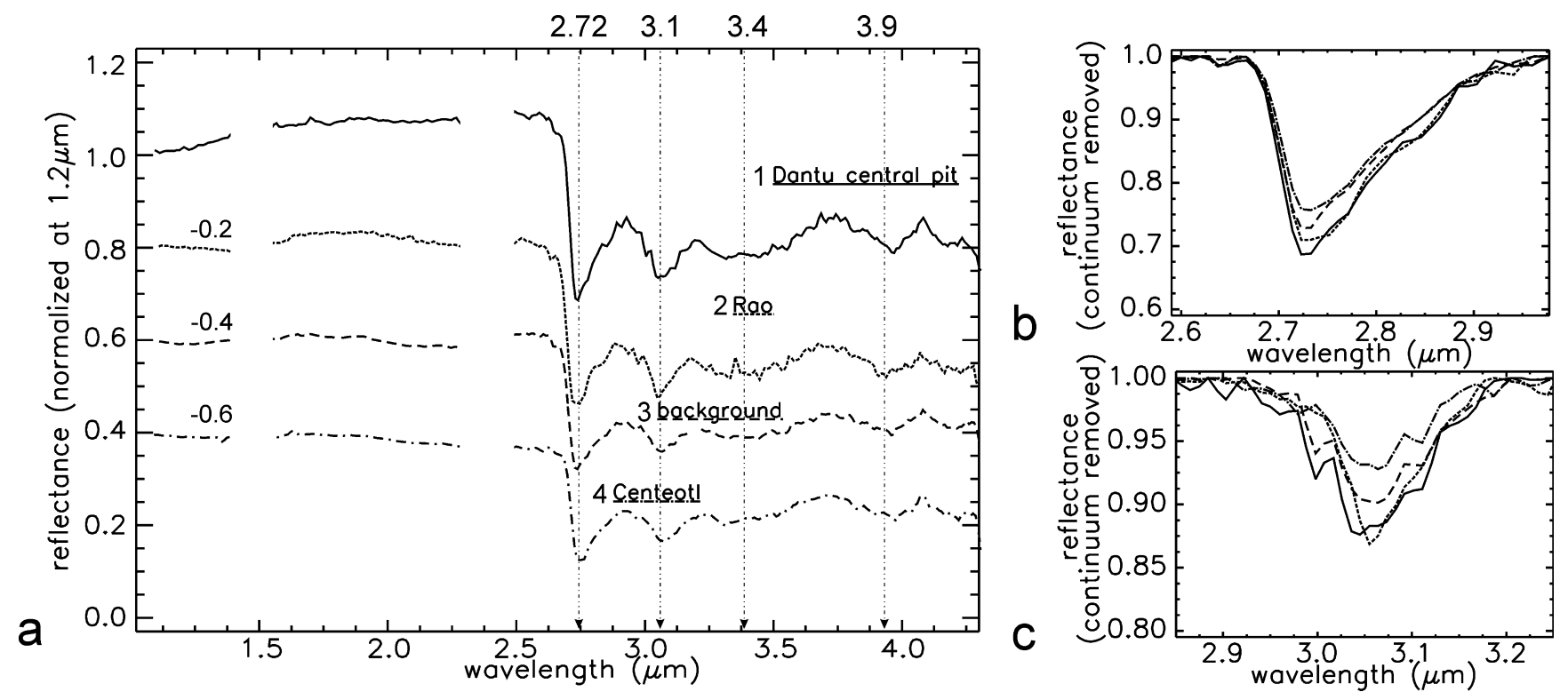

Fig. 5. VIR spectra of type localities dominated by phyllosilicates (a) with subsets of the absorptions at (b) 2.7 and (c) $3.1 \mu \mathrm{m}$. The locations, where the VIR spectra have been taken are shown in Fig. 6 a.

Dantu area studied here. The variations in the BD at $3.1 \mu \mathrm{m}$ rather imply that deep absorptions are associated with Dantu and its ejecta in the northern portion of the studied area, and extend across the Dantu area to the south in the direction of Kerwan including the impact craters Rao and Cacaguat.

\section{Carbonates}

Although the two absorptions centered near $~ 3.4$ and $\sim 3.95 \mu \mathrm{m}$, associated with carbonates (De Sanctis et al. 2016), appear in every VIR spectrum, they dominate the spectral signature of Dantu only in a few, spatially very limited visually bright spots. In Figs. 9 and 10, the locations and the corresponding VIR spectra of the best spatially resolved bright spots or clusters of bright spots are presented. These spots mostly correspond to bright spots indicated in the geological map in Fig. 2. Usually the spots are spatially very limited, do not exceed a few kilometers in size, and appear morphologically very young. Thus, not all bright spots identified in the FC images have been found to be rich in carbonate in the spatially lower resolved VIR data. Figure 11 shows a close-up view on the spectral properties of three type locations of the bright spots in the Dantu area. Either they are associated with mass wasting material located at steep crater walls (location of spectrum \#5) but can also be found in topographically flat areas on Dantu's crater floor (Fig. 2: geological unit cf) and within Dantu's ejecta blanket (Fig. 2, geological unit c). Bright spots on Dantu's floor (Fig. 11: locations of spectrum \#1 and \#8) lie in the vicinity of a set of fractures implying local tectonic resurfacing.

All VIR spectra in Fig. 10 exhibit strong carbonaterelated absorptions near $\sim 3.4$ and $\sim 3.95 \mu \mathrm{m}$ with BDs larger than 10 and $15 \%$, respectively. In comparison with the surrounding geologically old heavily cratered terrain of Dantu ("background" spectrum in Fig. 8), however, in the VIR spectra of the carbonate-enriched bright spots, the BCs of the $3.4 \mu \mathrm{m}$ and $3.95 \mu \mathrm{m}$ absorption slightly shift to longer wavelengths, i.e., $~ 3.5$ and $\sim 4 \mu \mathrm{m}$, respectively. This might be suggestive of changes in the chemistry of the carbonates and the possible appearance of Na-carbonates as the dominant species instead of $\mathrm{Ca} / \mathrm{Mg}$-carbonates in the common "background" material (De Sanctis et al. 2016; Palomba et al. 2016b; Longobardo et al. 2017b; Carrozzo et al. 2018).

The VIR spectra in Fig. 11 indicate a gradual change from the phyllosilicate-dominated spectrum of the "background" material to the carbonate-dominated spectrum of bright spot \#1. Although spectrum \#9 differs from the "background" only due to a slightly deeper absorption at $3.9 \mu \mathrm{m}$, the $\mathrm{BC}$ shifts to longer wavelength positions as the carbonate absorptions at 3.5 as well as $4 \mu \mathrm{m}$ become more prominent. Still, although the $\mathrm{BC}$ varies, the maxima bordering the carbonate absorptions do not vary between the spectra of the bright spots and the "background" material. Thus, it cannot be excluded that these variations are additionally influenced by the spatial resolution and size of the bright spots or the thickness of the carbonaterich surface layer. Thus, with increasing spatial 

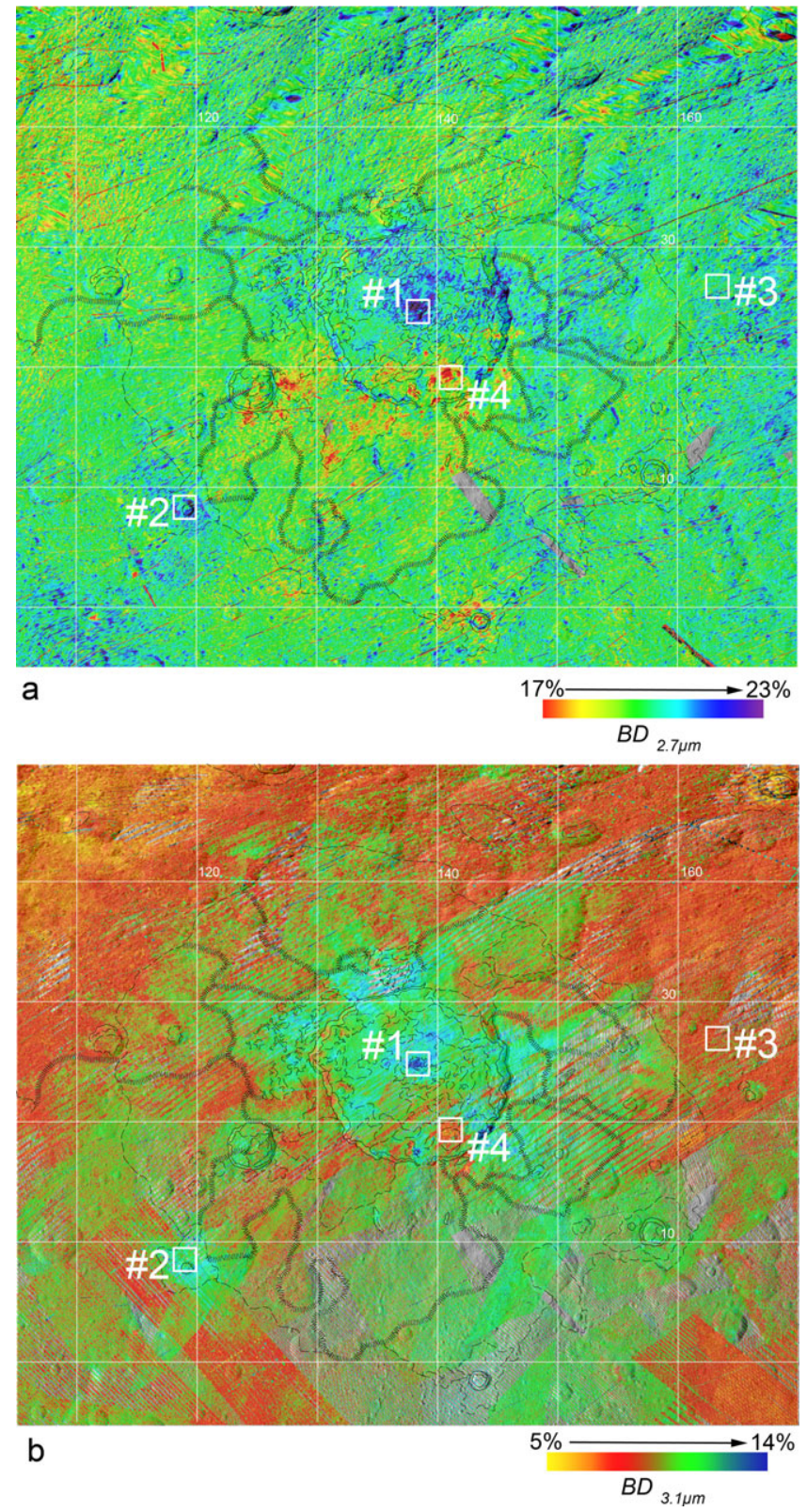

Fig. 6. VIR-derived spectral band depth maps of the Dantu region: (a) $\mathrm{BD}_{2.7 \mu \mathrm{m}}$ and (b) $\mathrm{BD}_{3.1 \mu \mathrm{m}}$. The white boxes indicate the locations of the VIR spectra shown in Fig. 5.

resolution, the spectral signature of the Na-bearing carbonates, with respect to the surrounding phyllosilicates, possibly becomes more prominent in the VIR spectra and the $\mathrm{BC}$ shifts due to the asymmetric shape of the absorptions at 3.5 and $4 \mu \mathrm{m}$.

The BDs of the absorptions at 2.7 and $3.1 \mu \mathrm{m}$ are either similar to or smaller than measured for the "background" material. This is a common behavior of bright spots (Palomba et al. 2016a). Thus, in the BD maps, these spots cannot be distinguished from small

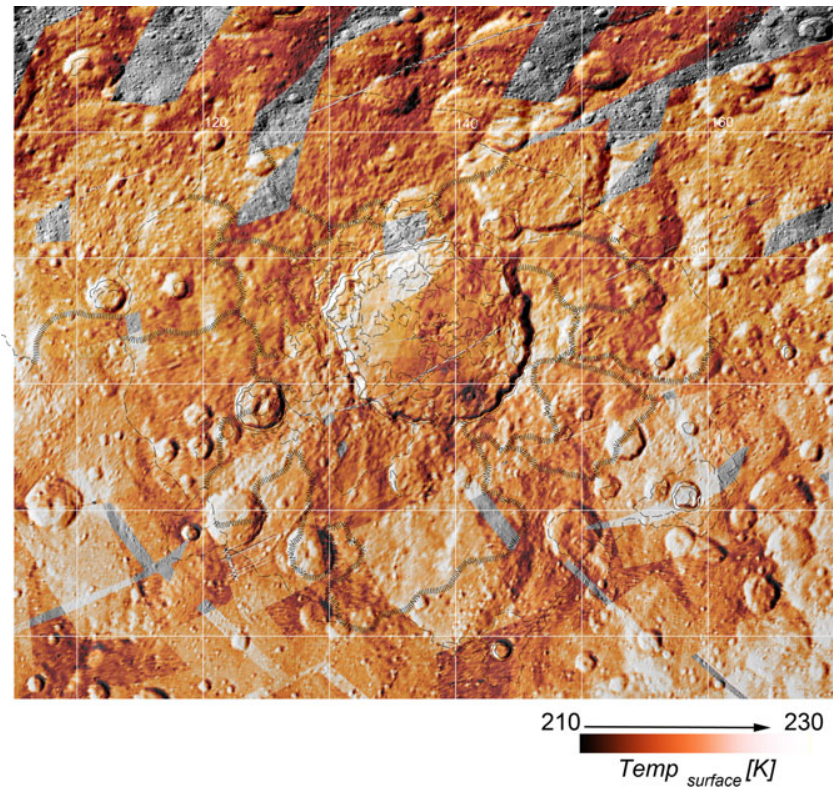

Fig. 7. VIR-derived surface temperature of the Dantu region at the time of the corresponding VIR observations. The majority of VIR observations used for the thermal analysis were acquired in the Cerean morning between 10 and $12 \mathrm{~h}$.

fresh impact craters such as Centeotl and Cacaguat (Figs. 8 and 11). Only in spectrum \#1, which shows the highest concentration of carbonates and two welldefined absorptions at $\sim 3.5$ and $\sim 4 \mu \mathrm{m}$ (Fig. 10), does the $\mathrm{BC}$ of the $\mathrm{OH}$-absorption shift from $\sim 2.72 \mu \mathrm{m}$ to slightly longer wavelengths at $\sim 2.76 \mu \mathrm{m}$. Furthermore, the spectrum exhibits a slightly different band shape, possibly pointing to hydrated material and a possible change in the composition of the phyllosilicates, i.e., Alinstead of Mg-phyllosilicates, as observed in Occator (De Sanctis et al. 2016; Palomba et al. 2016b; Longobardo et al. 2017b; Raponi et al. 2018a).

\section{$\mathrm{H}_{2} \mathrm{O}$ Ice}

$\mathrm{H}_{2} \mathrm{O}$ ice may be detected only in one small location in the vicinity of Dantu crater at $29.5^{\circ} \mathrm{N}$ and $155.1^{\circ} \mathrm{E}$ (Fig. 12). LAMO FC images with a resolution of $34 \mathrm{~m}$ per pixel reveal a $\sim 275 \mathrm{~m}$ small impact crater at this location with the bright icy areas covering the western portion of its crater wall (Fig. 13). The small crater is located on the southern rim of an older and larger crater and directly at the edge of Dantu's ejecta blanket (Fig. 2: geological unit c). At the given spatial resolution of the VIR HAMO data of $380 \mathrm{~m}$ per pixel, the $\mathrm{H}_{2} \mathrm{O}$ ice signature does not cover an entire pixel. Usually, the identification of $\mathrm{H}_{2} \mathrm{O}$ ice is very straightforward due to the existence of the numerous absorptions diagnostic of $\mathrm{H}_{2} \mathrm{O}$ ice. However, given the 

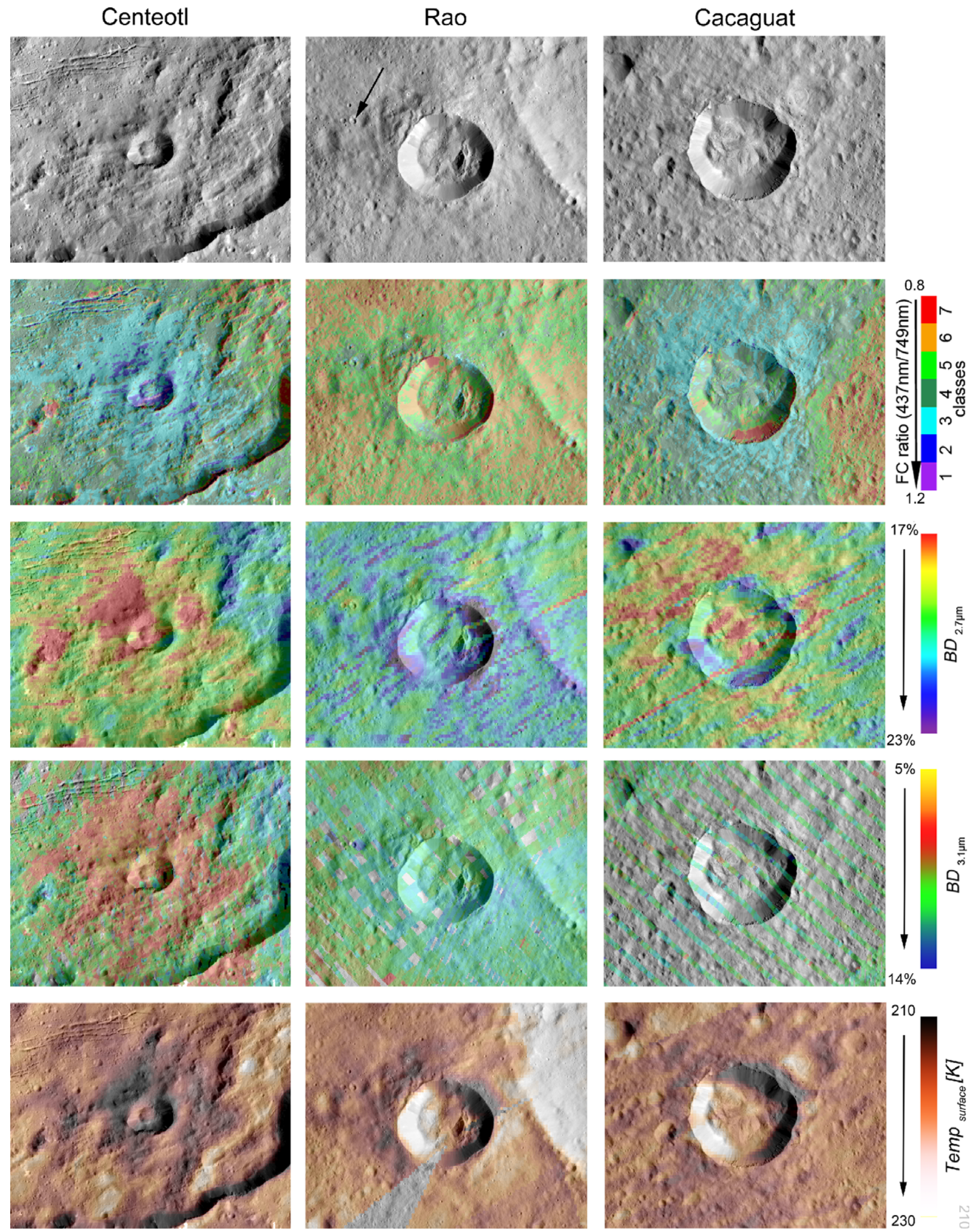
Fig. 8. Close-up views on the spectral properties of the impact craters Centeotl, Rao, and Cacaguat: FC clear filter image, FCderived ratio classes, band depth maps of the $\mathrm{BD}_{2.7 \mu \mathrm{m}}$ and $\mathrm{BD}_{3.1 \mu \mathrm{m}}$, and the surface temperature at the time of the VIR observation (from top to bottom row). The location of these impact craters is indicated in Fig. 1. Note the black arrow indicating one of the tiny fresh impact craters near Rao with spectral properties similar to Centeotl.

very low spatial resolution of the spot, the presumed $\mathrm{H}_{2} \mathrm{O}$ ice absorptions are very weak in the corresponding VIR spectrum. Still, these absorptions are recognizable in the ratio spectrum of the ice-rich spot and the direct surroundings. The actual wavelength positions of their $\mathrm{BCs}$ at $1.04,1.25,1.52$, and $2.02 \mu \mathrm{m}$ indicate crystalline $\mathrm{H}_{2} \mathrm{O}$ ice (Mastrapa and Brown 2006).

The spot is visible in all images of this area acquired during Dawn's HAMO and LAMO phase and in the FC images of Dawn's extended mission between August 2015 and October 2016. The top row in Fig. 13 shows FC images taken during the HAMO and the extended mission XMO2/CXJ orbit phase. The spot is clearly recognizable in all three images taken on August 25, 2015; September 25, 2015; and October 21, as a single bright pixel at the spatial resolution of $\sim 140 \mathrm{~m}$ per pixel. The bottom row shows five high-resolution images from LAMO and XMO2/CXL with $35 \mathrm{~m}$ per pixel spatial resolution. The spot measures several pixels across and is clearly associated with the interior of the small crater. The five images were taken on December 19, 2015; January 11, 2016; February 2, 2016; May 15, 2016; and August 21, 2016. Taking the differences in the spatial resolution of the FC images into account, no significant changes in the visible albedo and the spatial extent of the spot could be determined. The highest albedo of 0.25 could be measured in the LAMO images of FC filter $2(550 \mathrm{~nm})$, whereas the surrounding region exhibits a distinctly lower albedo of $\sim 0.05$. In summary, the bright icy spot has been visible in the FC images for 422 Earth days, which is about one quarter of a Cerean year.

\section{DISCUSSION OF THE OBSERVED SPECTRAL VARIATIONS AND IMPLICATIONS FOR THE GEOCHEMICAL EVOLUTION OF THE DANTU AREA}

The investigation of Dantu's surface composition revealed that Dantu not only exhibits a complex geology/morphology but also displays a multifaceted surface composition. The spectral properties of Dantu and its direct surroundings exhibit a pronounced heterogeneity in the surface composition. Most of the surface compounds, which have been identified on Ceres by VIR (except organic material) (De Sanctis et al. 2015) also occur in the vicinity of Dantu. Furthermore, the investigation of the spectral signatures of the surface compounds of the Dantu area as derived from the VIR spectra reveals different spatial variations with respect to each other implying several surface processes during the geochemical evolution of the Dantu area that are responsible for their appearance or formation.

Regions that have been found to be enriched in $\mathrm{NH}_{4}$-bearing phyllosilicates, which include Dantu itself and extend to the south toward Kerwan (Palomba et al. 2017a), correspond quite well with the proposed location of Vendimia Planitia, which has been interpreted as an ancient impact basin (Marchi et al. 2016), where material from an ammonium-enriched region in the deeper Ceres's crust could have been excavated (Stephan et al. 2017c). An increasing abundance of $\mathrm{NH}_{4}$ in a deeper crustal region would strengthen the theory that ammonia is a primordial constituent of Ceres that possibly has been accreted as organic matter or as ice and may have reacted with phyllosilicates during Ceres's differentiation (De Sanctis et al. 2015). The highest concentration of $\mathrm{NH}_{4}$ in Dantu central peak material supports this hypothesis. It is presumably composed of crustal material uplifted during the latter stages of the impact event and commonly originates from the deeper portions of the crust material below the crater floor that became excavated during the impact (Melosh 1989; Wieczorek and Zuber 2001; Cahill et al. 2009). Also, the concentration of $\mathrm{NH}_{4}$ in the crater and ejecta material of the geologically younger impact craters Rao and Cacaguat are consistent with this scenario, since they have been emplaced within the presumed region of Vendimia Planitia where the measured $B D$ s conform to the generally strong absorptions in the entire basin (Stephan et al. 2017c).

However, this does not answer the question of why the spectral signatures of these two impact craters are different from the impact crater Centeotl located on Dantu's floor. Centeotl is one of numerous impact craters on Ceres emplaced during the youngest era (Azaccan) of Ceres's geological history (Mest et al. 2017), which have been found to be depleted in $\mathrm{NH}_{4}$ and $\mathrm{OH}^{-}$and exhibit a bluish visible spectral slope (Stephan et al. 2017a). Generally, the strength of individual absorptions can be influenced by a varying abundance or the physical properties of the phyllosilicates. In contrast to Centeotl, the bright spots in the Dantu area show a higher concentration of carbonates, which could subdue the absorptions at 2.7 


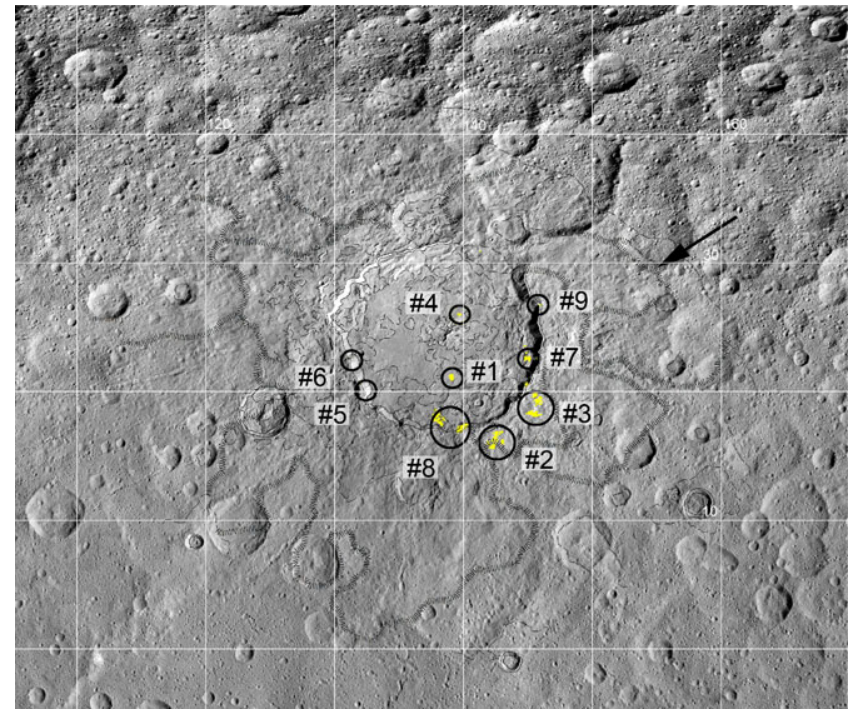

Fig. 9. Locations of bright spots in the vicinity of Dantu, which are enriched in carbonates with the corresponding VIR spectra presented in Fig. 10. Close-up views of the bestresolved bright spots $(\# 1, \# 5, \# 8)$ are shown in Fig. 11.

and $3.1 \mu \mathrm{m}$ in the spectral mixture. The VIR spectrum of Centeotl, however, still shows a dominating signature of phyllosilicates implying that no significant differences in the surface composition occur in comparison with the surface composition of Dantu's central peak and Rao (Fig. 5). Thus, differences in the physical rather than chemical properties of the surface material could possibly explain Centeotl's spectral characteristics. The visible spectral slope is known to be related to increasing grain size of the surface material. On Ceres, however, the "bluing" of the visible spectral slope is also strongly related to a weakening of the $\mathrm{OH}$ absorption at $2.7 \mu \mathrm{m}$ (Stephan et al. 2017a). By taking into account the geomorphological appearance of this surface material, which can be described as mostly very smooth and often related to flows of possibly melted ejecta material (Krohn et al. 2016), aggregates or agglomerates of ultrafine (partly amorphous) material enriched in phyllosilicates, which can be easily formed during the impact event (Stephan et al. 2017a) could offer one explanation. Impact events are clearly expected to affect at least the physical properties of the phyllosilicates either by grinding/brecciation and/or heating/melting. Laboratory experiments show a bluing of the spectral slope due to amorphization and agglomeration of fine phyllosilicate particles (Bishop et al. 2008), which both resemble effects expected during an impact event. The resulting agglomerates of fine grains could mimic a spectral signature of larger grains, i.e., resemble the effect of larger grains, which cause the "bluing." Intriguingly, experiments also showed a

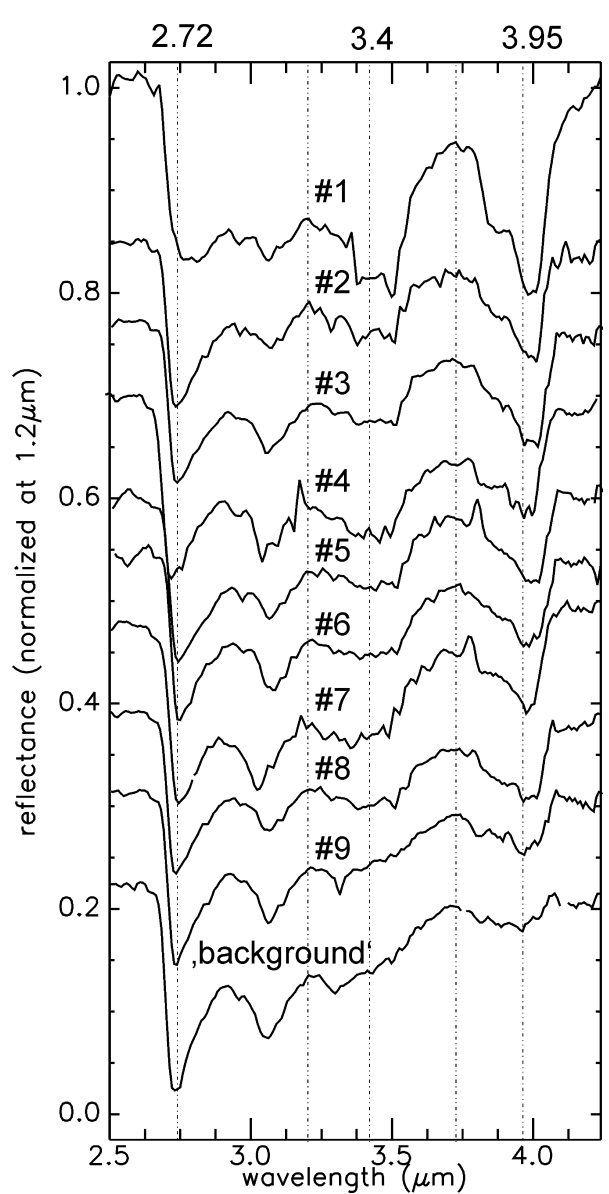

Fig. 10. VIR-IR spectra selected for the bright spots in the vicinity of Dantu, which are enriched in carbonates. The locations where the VIR spectra were taken are shown in Fig. 9.

decrease of the $2.7 \mu \mathrm{m}$ absorptions, possibly implying some dehydration during the process. The bluish visible spectral slope diminishes slowly with increasing geologic age due to particle size changes as a result of space weathering processes including micrometeoritic impacts and/or due to changes of porosity and sorting as a result of redeposition by gravitationally caused slumping of fine and loosely consolidated regolith (Stephan et al. 2017c).

Geomorphologically, the bright spots enriched in carbonates appear to be the youngest surface material in the vicinity of Dantu. Their formation and possible relation to the Dantu impact event, however, is not fully resolved. Nevertheless, the "freshest" and spectrally most distinct example that occurs in topographically flat regions on Dantu's crater floor in the vicinity of sets of inner-crater fractures is spectrally as well as geomorphologically very similar to the prominent Ceralia and Vinalia facula in Occator crater (De Sanctis et al. 2016; Longobardo et al. 2017a; Palomba et al. 

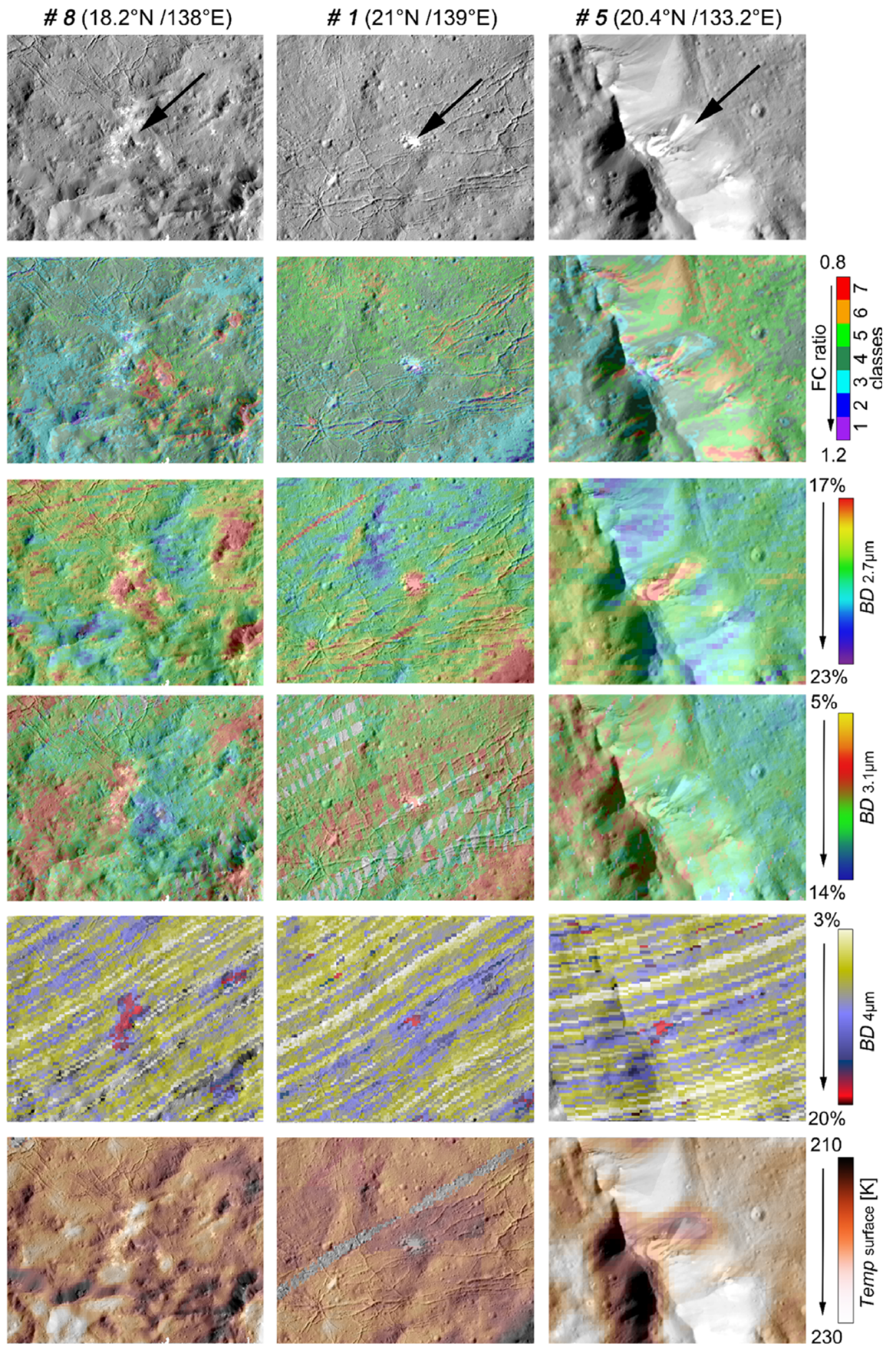

Fig. 11. Close-up view on the spectral properties of the best-resolved visually bright spots enriched in carbonates: FC clear filter image, FC-derived ratio classes (see Fig. 4), band depth maps of the $\mathrm{BD}_{2.7} \mu \mathrm{m}, \mathrm{BD}_{3.1} \mu \mathrm{m}$, and $\mathrm{BD}_{4}$ um, as well as the surface temperature at the time of the VIR observation (from top to bottom row). The locations of the bright spots in the field of view are indicated in the FC clear filter images by black arrows and their location in the Dantu area are included in Fig. 9. 

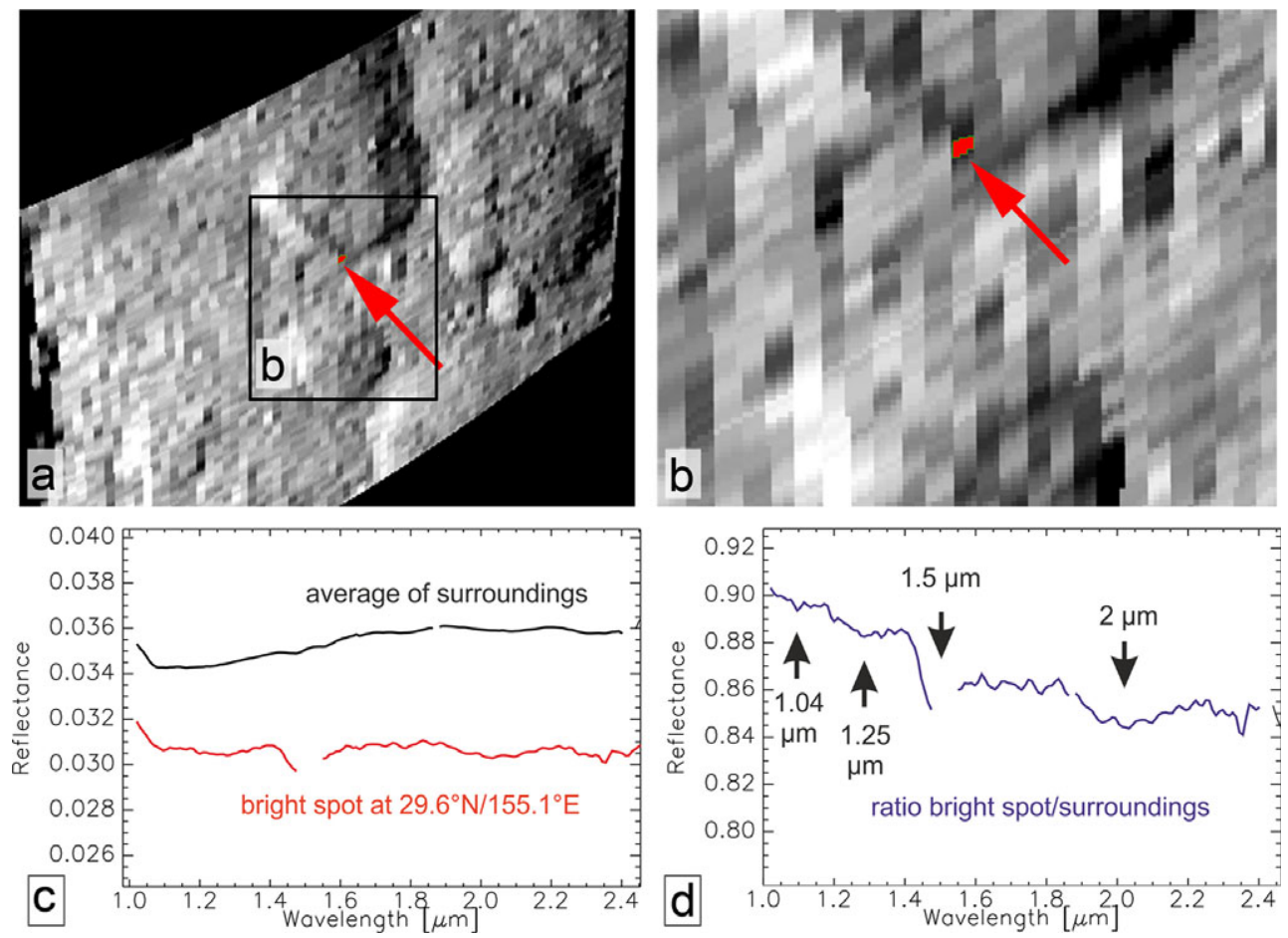

Fig. 12. The location of the identified $\mathrm{H}_{2} \mathrm{O}$ ice-rich spot (indicated by the red dot) in the (a) full and (b) subset of the VIR observation 494522179 (HAMO), (c) the corresponding VIR spectra of the icy spot and the direct surroundings, and (d) the corresponding VIR ratio spectrum showing the $\mathrm{H}_{2} \mathrm{O}$ ice absorptions at $1.04,1.25,1.5$, and $2 \mu \mathrm{m}$.

2017b), which have been interpreted to be formed due to impact-induced heating and upwelling of volatile-rich materials, upwelling/excavation of heterogeneously distributed subsurface brines or their precipitation products, or a combination of both processes (Stein et al. 2017). The particular association of carbonate-rich bright spots with Dantu's crater walls and ejecta could point to the excavation of subsurface bright material, possibly from floor facula that were previously emplaced and buried. Other impact events might also play a part in the (re-)distribution of the carbonates in the Dantu region. Possibly, they represent ejecta material originating from Kokopelli southwest of Dantu (Fig. 1).

The spectral properties of the bright spots in the vicinity of Dantu correspond to the findings of Palomba et al. (2017b), who proposed an evolutionary path from initially fresh bright spots such as the faculae in Occator, whose salts and $\mathrm{OH}$ volatilize and start to mix with surrounding material. The possibly hydrated carbonates of the "freshest" bright spot on Dantu's floor might imply that $\mathrm{H}_{2} \mathrm{O}$ ice still exists at least locally in Dantu's subsurface, which could also explain the existence of the tiny $\mathrm{H}_{2} \mathrm{O}$ ice-rich spot detected near Dantu. Possibly more spots enriched in $\mathrm{H}_{2} \mathrm{O}$ ice exist in this region but are spatially below the detection limit, i.e., the pixel resolution of the available VIR data.
Investigations by GRaND support the widespread occurrence of $\mathrm{H}_{2} \mathrm{O}$ ice in Ceres's subsurface with increasing abundance in the first few tens of centimeters toward the polar regions (Prettyman et al. 2017). On the Cerean surface, however, $\mathrm{H}_{2} \mathrm{O}$ ice is not stable at the typical temperatures of Ceres's dayside. Models only support the time-limited existence of $\mathrm{H}_{2} \mathrm{O}$ ice at moderate to high latitudes or in shadows (Hayne and Aharonson 2015). Indeed, the majority of icy spots on Ceres have been identified at relatively high latitudes of $> \pm \sim 50^{\circ}$, where surface temperature is lower and larger portions of the surface area are almost permanently shielded from sunlight or poorly illuminated by the Sun (Combe et al. 2016; Raponi et al. 2018b). The $\mathrm{H}_{2} \mathrm{O}$ icerich spot near Dantu, however, is located at relatively low latitude, where $\mathrm{H}_{2} \mathrm{O}$ ice should sublimate in a short period of time. Nevertheless, Hayne and Aharonson (2015) postulated that ice deposits at $\sim 20^{\circ} \mathrm{N}$ would have a lifetime not longer than $\sim 100$ years. Another detection of $\mathrm{H}_{2} \mathrm{O}$ ice at midlatitudes, which has been reported to be associated with a shadowed region of the rim of impact crater Juling $\left(35.9^{\circ} \mathrm{S} / 168.5^{\circ} \mathrm{E}\right.$, diameter: $\left.20 \mathrm{~km}\right)$, showed that the amount of $\mathrm{H}_{2} \mathrm{O}$ ice was not constant but variable during a few months of observations, reinforcing the instability of $\mathrm{H}_{2} \mathrm{O}$ ice at such low latitudes (Raponi et al. 2018b). 


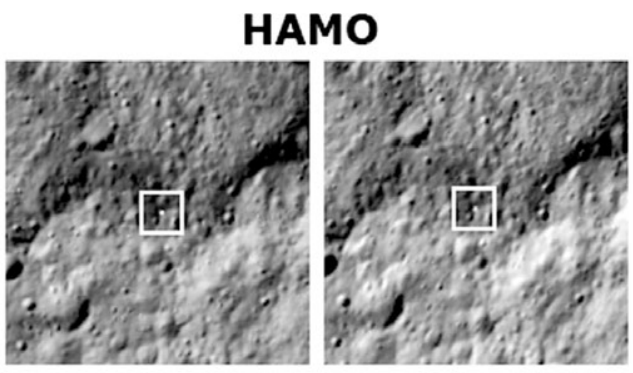

$10 \mathrm{~km}$

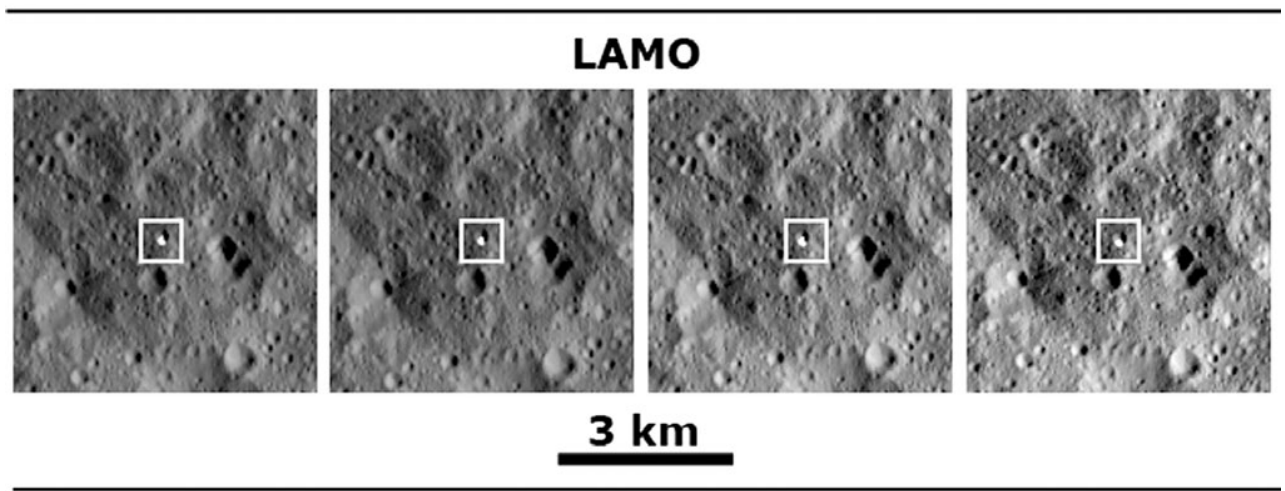

\section{XM01/CXL XMO2/CXJ}

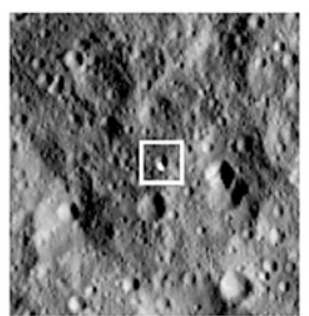

$3 \mathbf{~ k m}$

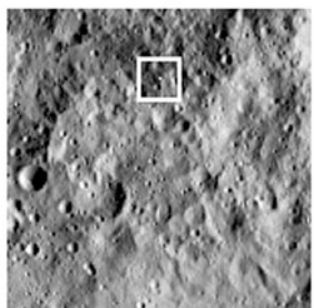

$10 \mathrm{~km}$

Fig. 13. The identified $\mathrm{H}_{2} \mathrm{O}$ ice-rich spot as observed in $\mathrm{FC}$ images acquired throughout the HAMO, LAMO, and extended Dawn mission phase (XMO2/CXL). The HAMO and XMO2/CXL images were acquired on August 25, September 25 in 2015, as well as October 21, 2016 with a spatial resolution of $\sim 140 \mathrm{~m}$ per pixel. The LAMO images, which show the area with a spatial resolution of 35 m per pixel, were taken on December 19, 2015; January 11, 2016; February 2, 2016; May 15, 2016; and August 21, 2016.

Thus, either the $\mathrm{H}_{2} \mathrm{O}$ ice spot near Dantu represents remnants of ice-rich impactor material or it became excavated from the subsurface. It is questionable that the $\mathrm{H}_{2} \mathrm{O}$ ice of an ice-rich impactor would not have been completely sublimated. This spot lies outside of Dantu crater, but it is closely located to the outer boundary of Dantu's continuous ejecta, which have been excavated during the first stage of the impact event or by a secondary impact. Therefore, it is more presumable that locally $\mathrm{H}_{2} \mathrm{O}$ ice still exists in proximity to the surface, possibly additionally covered by the Dantu ejecta blanket, and could have been excavated from the subsurface by a recent small impact, where the $\mathrm{H}_{2} \mathrm{O}$ ice is still present in the crater wall.
Acknowledgments-We thank the Dawn team for the development, cruise, orbital insertion, and operations of the Dawn spacecraft at Ceres. Portions of this work were performed at the DLR Institute of Planetary Research, at the INAF-Istituto di Astrofisica e Planetologia Spaziali, Rome-Italy, as well as the Jet Propulsion Laboratory (JPL) under contract with NASA. VIR is funded by the Italian Space Agency and was developed under the leadership of INAF-Istituto di Astrofisica e Planetologia Spaziali, Rome, Italy. Part of this work was supported by the Italian Space Agency. Dawn data are archived with the NASA Planetary Data System (http://sbn.pds.nasa.gov/). Finally we thank C. M. Pieters and M. Toplis for their thoughtful comments 
and suggestions, which considerably improved our manuscript.

\section{Editorial Handling-Dr. Michael Toplis}

\section{REFERENCES}

Ammannito E., De Sanctis M. C., Carrozzo F. G., Zambon F., Ciarniello M., Combe J. P., Frigeri A., Longobardo A., Raponi A., Tosi F., Fonte S., Giardino M., McFadden L. A., Palomba E., Stephan K., Raymond C. A., and Russell C. T. 2016a. Composition of the Urvara-Yalode Region on Ceres. Proceedings GSA Annual Meeting, Denver, Colorado, USA. Volume 48.

Ammannito E., DeSanctis M. C., Ciarniello M., Frigeri A., Carrozzo F. G., Combe J.-P., Ehlmann B. L., Marchi S., McSween H. Y., Raponi A., Toplis M. J., Tosi F., Castillo-Rogez J. C., Capaccioni F., Capria M. T., Fonte S., Giardino M., Jaumann R., Longobardo A., Joy S. P., Magni G., McCord T. B., McFadden L. A., Palomba E., Pieters C. M., Polanskey C. A., Rayman M. D., Raymond C. A., Schenk P. M., Zambon F., and Russell C. T. 2016b. Distribution of phyllosilicates on the surface of Ceres. Science 353:aaf4279.

Bishop J. L., Dyar M. D., Sklute E. C., and Drief A. 2008. Physical alteration of antigorite: A Mössbauer spectroscopy, reflectance spectroscopy and TEM study with applications to Mars. Clay Minerals 43:55-67.

Cahill J. T. S., Lucey P. G., and Wieczorek M. A. 2009. Compositional variations of the lunar crust: Results from radiative transfer modeling of central peak spectra. Journal of Geophysical Research: Planets 114. https://doi.org/10. 1029/2008je003282

Carrozzo F. G., Raponi A., Sanctis M. C. D., Ammannito E., Giardino M., D'Aversa E., Fonte S., and Tosi F. 2016. Artifacts reduction in VIR/Dawn data. Review of Scientific Instruments 87:124501.

Carrozzo F. G., De Sanctis M. C., Ammannito E., Ciarniello M., Frigeri A., Raponi A., Zambon F., Tosi F., Combe J.-P., Longobardo A., McFadden L. A., Palomba E., Pieters C., Stephan K., Raymond C. A., and Russell C. T. 2017. Spectral analysis of the Quadrangle Ac-H-08 Nawish on Ceres. 48th Lunar and Planetary Science Conference. CD-ROM.

Carrozzo F. G., De Sanctis M. C., Raponi A., Ammannito E., Castillo-Rogez J., Ehlmann B. L., Marchi S., Stein N., Ciarniello M., Tosi F., Capaccioni F., Capria M. T., Fonte S., Formisano M., Frigeri A., Giardino M., Longobardo A., Magni G., Palomba E., Zambon F., Raymond C. A., and Russell C. T. 2018. Nature, formation, and distribution of carbonates on Ceres. Science Advances 4:e1701645.

Clark R. N. 2003. Imaging spectroscopy: Earth and planetary remote sensing with the USGS Tetracorder and expert systems. Journal of Geophysical Research 108:5131-5131.

Combe J.-P., McCord T. B., Tosi F., Ammannito E., Carrozzo F. G., De Sanctis M. C., Raponi A., Byrne S., Landis M. E., Hughson K. H. G., Raymond C. A., and Russell C. T. 2016. Detection of local $\mathrm{H}_{2} \mathrm{O}$ exposed at the surface of Ceres. Science 353:aaf3010.

De Sanctis M. C., Coradini A., Ammannito E., Filacchione G., Capria M. T., Fonte S., Magni G., Barbis A., Bini A., Dami M., Ficai-Veltroni I., and Preti G. 2011. The VIR spectrometer. Space Science Reviews 163:329-369.
De Sanctis M. C., Ammannito E., Raponi A., Marchi S., McCord T. B., McSween H. Y., Capaccioni F., Capria M. T., Carrozzo F. G., Ciarniello M., Longobardo A., Tosi F., Fonte S., Formisano M., Frigeri A., Giardino M., Magni G., Palomba E., Turrini D., Zambon F., Combe J.-P., Feldman W., Jaumann R., McFadden L. A., Pieters C. M., Prettyman T., Toplis M., Raymond C. A., and Russell C. T. 2015. Ammoniated phyllosilicates with a likely outer solar system origin on (1) Ceres. Nature 528:241-244.

De Sanctis M. C., Raponi A., Ammannito E., Ciarniello M., Toplis M. J., McSween H. Y., Castillo-Rogez J. C., Ehlmann B. L., Carrozzo F. G., Marchi S., Tosi F., Zambon F., Capaccioni F., Capria M. T., Fonte S., Formisano M., Frigeri A., Giardino M., Longobardo A., Magni G., Palomba E., McFadden L. A., Pieters C. M., Jaumann R., Schenk P., Mugnuolo R., Raymond C. A., and Russell C. T. 2016. Bright carbonate deposits as evidence of aqueous alteration on (1) Ceres. Nature 536:54-57.

De Sanctis M. C., Ammannito E., McSween H. Y., Raponi A., Marchi S., Capaccioni F., Capria M. T., Carrozzo F. G., Ciarniello M., Fonte S., Formisano M., Frigeri A., Giardino M., Longobardo A., Magni G., McFadden L. A., Palomba E., Pieters C. M., Tosi F., Zambon F., Raymond C. A., and Russell C. T. 2017. Localized aliphatic organic material on the surface of Ceres. Science 355:719-722.

Filacchione G., Ammannito E., Coradini A., deSanctis M. C., Capaccioni F., Capria M. T., Carraro F., Cartacci M., Fonte S., Noschese R., and Tosi F. 2011. Validating Dawn/VIR-MS VIS-IR spectrometer calibration at Vesta, EPSC-DPS Joint Meeting 2011. 832 p.

Frigeri A., De Sanctis M. C., Ammannito E., Carrozzo G., Williams D., Mest S., Buczkowski D., Preusker F., Jaumann R., Roatsch T., Scully J., Kneissl T., Raymond C. A., and Russell C. T. 2016. Geologic Mapping of the AC-H-08 Nawish Quadrangle of Ceres from NASA's Dawn Mission (abstract \#2271). 47th Lunar and Planetary Science Conference. CD-ROM.

Hayne P. O. and Aharonson O. 2015. Thermal stability of ice on Ceres with rough topography. Journal of Geophysical Research (Planets) 120:1567-1584.

Hiesinger H., Marchi S., Schmedemann N., Schenk P., Pasckert J. H., Neesemann A., O'Brien D. P., Kneissl T., Ermakov A. I., Fu R. R., Bland M. T., Nathues A., Platz T., Williams D. A., Jaumann R., Castillo-Rogez J. C., Ruesch O., Schmidt B., Park R. S., Preusker F., Buczkowski D. L., Russell C. T., and Raymond C. A. 2016. Cratering on Ceres: Implications for its crust and evolution. Science 353:aaf4759.

Kneissl T., Schmedemann N., Neesemann A., Williams D. A., Crown D. A., Mest S. C., Buczkowski D. L., Scully J. E. C., Frigeri A., Ruesch O., Hiesinger H., Walter S. H. G., Jaumann R., Roatsch T., Preusker F., Kersten E., Nass A., Nathues A., Platz T., Hoffmann M., Schaefer M., De Sanctis M. C., Raymond C. A., and Russell C. T. 2016. Geologic Mapping of the Ac-H-3 Dantu Quadrangle of Ceres from NASA's Dawn Mission (abstract \#1967). 47th Lunar and Planetary Science Conference. CD-ROM.

Krohn K., Jaumann R., Stephan K., Otto K. A., Schmedemann N., Wagner R. J., Matz K. D., Tosi F., Zambon F., von der Gathen I., Schulzeck F., Schröder S. E., Buczkowski D. L., Hiesinger H., McSween H. Y., Pieters C. M., Preusker F., Roatsch T., Raymond C. A., Russell C. T., and Williams D. A. 2016. Cryogenic flow 
features on Ceres: Implications for crater-related cryovolcanism. Geophysical Research Letters 43:11,99412,003 .

Longobardo A., Palomba E., Carrozzo F. G., Galiano A., De Sanctis M. C., Stephan K., Tosi F., Raponi A., Ciarniello M., Zambon F., Frigeri A., Ammannito E., Raymond C. A., and Russell C. T. 2017a. Mineralogy of the Occator quadrangle. Icarus. https://doi.org/10.1016/j.icarus.2017.09.022

Longobardo A., Palomba E., De Sanctis M. C., Carrozzo F. G., Galiano A., Tosi F., Zambon F., Raponi A., Ciarniello M., Ammannito E., Stephan K., McFadden L. A., Capria M. T., Fonte S., Giardino M., Raymond C. A., and Russell C. T. 2017b. Mineralogical mapping of the Occator quadrangle (abstract \#1964). 48th Lunar and Planetary Science Conference. CD-ROM.

Marchi S., Ermakov A. I., Raymond C. A., Fu R. R., O’Brien D. P., Bland M. T., Ammannito E., De Sanctis M. C., Bowling T., Schenk P., Scully J. E. C., Buczkowski D. L., Williams D. A., Hiesinger H., and Russell C. T. 2016. The missing large impact craters on Ceres. Nature Communications 7:12,257.

Mastrapa R. M. E., and Brown R. H. 2006. Ion irradiation of crystalline $\mathrm{H}_{2} \mathrm{O}$-ice: Effect on the $1.65 \mathrm{~m}$ band. Icarus 183:207-214.

Melosh H. J. 1989. Impact cratering: A geologic process. New York: Oxford University Press.

Mest S. C., Crown D. A., Yingst R. A., Berman D. C., Williams D. A., Buczkowski D. L., Scully J. E. C., Platz T., Jaumann R., Preusker F., Nathues A., Hiesinger H., Pasckert J. H., Raymond C. A., Russell C. T., and Team D. S. 2017. The global geologic map of Ceres based on Dawn HAMO observations (abstract \#2512). 48th Lunar and Planetary Science Conference. CD-ROM.

Palomba E., Longobardo A., De Sanctis M. C., Ammannito E., Carrozzo F. G., Raponi A., Ciarniello M., Frigeri A., Capria M. T., Tosi F., Zambon F., Fonte S., Giardino M., Capaccioni F., Raymond C. A., Russell C. T., and Pieters C. M. 2016a. Compositional characteristics of Ceres bright spots (abstract \#2198). 47th Lunar and Planetary Science Conference. CD-ROM.

Palomba E., Longobardo A., De Sanctis M. C., Stein N., Ehlmann B., Ammannito E., Giacomo Carrozzo F., Raponi A., Ciarniello M., Frigeri A., Capria M. T., Tosi F., Zambon F., Fonte S., Giardino M., Capaccioni F., Raymond C., and Russell C. T., and Team V.-D. 2016b. Compositional differences among Bright Spots on the Ceres surface, AAS/Division for Planetary Sciences Meeting Abstracts, Volume 48.

Palomba E., Longobardo A., De Sanctis M. C., Carrozzo F. G., Galiano A., Zambon F., Raponi A., Ciarniello M., Stephan K., Williams D. A., Ammannito E., Capria M. T., Fonte S., Giardino M., Tosi F., Raymond C. A., and Russell C. T. 2017a. Mineralogical mapping of the Kerwan quadrangle on Ceres. Icarus. https://doi.org/10. 1016/j.icarus.2017.07.021

Palomba E., Longobardo A., De Sanctis M. C., Stein N. T., Ehlmann B., Galiano A., Raponi A., Ciarniello M., Ammannito E., Cloutis E., Carrozzo F. G., Capria M. T., Stephan K., Zambon F., Tosi F., Raymond C. A., and Russell C. T. 2017b. Compositional differences among Bright Spots on the Ceres surface. Icarus. https://doi.org/ 10.1016/j.icarus.2017.09.020

Prettyman T. H., Yamashita N., Toplis M. J., McSween H. Y., Schörghofer N., Marchi S., Feldman W. C., Castillo-
Rogez J., Forni O., Lawrence D. J., Ammannito E., Ehlmann B. L., Sizemore H. G., Joy S. P., Polanskey C. A., Rayman M. D., Raymond C. A., and Russell C. T. 2017. Extensive water ice within Ceres' aqueously altered regolith: Evidence from nuclear spectroscopy. Science 355:55-59.

Preusker F., Scholten F., Matz K.-D., Elgner S., Jaumann R., Roatsch T., Joy S. P., Polanskey C. A., Raymond C. A., and Russell C. T. 2016. Dawn at Ceres-Shape model and rotational state (abstract \#1954). 47th Lunar and Planetary Science Conference. CD-ROM.

Raponi A. 2015. Spectrophotometric analysis of cometary nuclei from in situ observations Ph.D. thesis, ArXiv eprints, Volume 1503.

Raponi A., De Sanctis M. C., Carrozzo F. G., Ciarniello M., Castillo-Rogez J. C., Ammannito E., Frigeri A., Longobardo A., Palomba E., Tosi F., Zambon F., Raymond C. A., and Russell C. T. 2018a. Mineralogy of Occator crater on Ceres and insight into its evolution from the properties of carbonates, phyllosilicates, and chlorides. Icarus. https://doi.org/10.1016/j.icarus.2018.02.001

Raponi A., De Sanctis M. C., Frigeri A., Ammannito E., Ciarniello M., Formisano M., Combe J.-P., Magni G., Tosi F., Carrozzo F. G., Fonte S., Giardino M., Joy S. P., Polanskey C. A., Rayman M. D., Capaccioni F., Capria M. T., Longobardo A., Palomba E., Zambon F., Raymond C. A., and Russell C. T. 2018b. Variations in the amount of water ice on Ceres' surface suggest a seasonal water cycle. Science Advances 4:eaao3757.

Roatsch T., Kersten E., Matz K.-D., Preusker F., Scholten F., Jaumann R., Raymond C. A., and Russell C. T. 2016. High-resolution Ceres high altitude mapping orbit atlas derived from Dawn framing camera images. Planetary and Space Science 129:103-107.

Russell C. T. and Raymond C. A. 2011. The Dawn mission to Vesta and Ceres. Space Science Reviews 163:3-23.

Russell C. T., Nathues A., Li J.-Y., McCord T. B., Raymond C., Jaumann R., Prettyman T., De Sanctis M. C., McSween H. P., Schenk P., O'Brien D. P., Denevi B., and Marchi S. 2012. Dawn at Vesta: Paradigm based on HED meteorites confirmed but surprises abound. 39th COSPAR Scientific Assembly, Volume 39, 1633 p.

Russell C. T., Raymond C. A., Ammannito E., Buczkowski D. L., De Sanctis M. C., Hiesinger H., Jaumann R., Konopliv A. S., McSween H. Y., Nathues A., Park R. S., Pieters C. M., Prettyman T. H., McCord T. B., McFadden L. A., Mottola S., Zuber M. T., Joy S. P., Polanskey C., Rayman M. D., Castillo-Rogez J. C., Chi P. J., Combe J. P., Ermakov A., Fu R. R., Hoffmann M., Jia Y. D., King S. D., Lawrence D. J., Li J.-Y., Marchi S., Preusker F., Roatsch T., Ruesch O., Schenk P., Villarreal M. N., and Yamashita N. 2016. Dawn arrives at Ceres: Exploration of a small, volatile-rich world. Science 353:1008-1010.

Schmedemann N., Neesemann A., Schulzeck F., Krohn K., dervon Gathen I., Otto K. A., Jaumann R., Michael G., Raymond C. A., and Russell C. T. 2017. The distribution of impact ejecta on Ceres (abstract \#1233). 48th Lunar and Planetary Science Conference. CD-ROM.

Schröder S. E., Mottola S., Keller H. U., Raymond C. A., and Russell C. T. 2013. Resolved photometry of Vesta reveals physical properties of crater regolith. Planetary and Space Science 85:198-213.

Sierks H., Keller H. U., Jaumann R., Michalik H., Behnke T., Bubenhagen F., Büttner I., Carsenty U., Christensen U., 
Enge R., Fiethe B., Gutiérrez Marqués P., Hartwig H., Krüger H., Kühne W., Maue T., Mottola S., Nathues A., Reiche K.-U., Richards M. L., Roatsch T., Schröder S. E., Szemerey I., and Tschentscher M. 2011. The Dawn framing camera. Space Science Reviews 163:263-327.

Stein N., Ehlmann B., Ammannito E., Palomba E., De Sanctis M. C., Jaumann R., Nathues A., Raymond C. A., Hiesinger H., Schenk P., and Longobardo A. 2017. Characteristics, formation, and evolution of faculae (bright spots) on Ceres (abstract \#2547). 48th Lunar and Planetary Science Conference. CD-ROM.

Stephan K., Jaumann R., Krohn K., Schmedemann N., Zambon F., Tosi F., Carrozzo F. G., McFadden L. A., Otto K., De Sanctis M. C., Ammannito E., Matz K. D., Roatsch T., Preusker F., Raymond C. A., and Russell C. T. 2017a. An investigation of the bluish material on Ceres. Geophysical Research Letters 44:1660-1668.

Stephan K., Jaumann R., Zambon F., Carrozzo F. G., De Sanctis M. C., Tosi F., Longobardo A., Palomba E., Ammannito E., McFadden L. A., Krohn K., Williams D. A., Raponi A., Ciarnello M., Combe J. P., Frigeri A., Roatsch T., Matz K. D., Preusker F., Raymond C. A., and Russell C. T. $2017 \mathrm{~b}$. Spectral investigation of quadrangle AC-H 3 of the dwarf planet Ceres-The region of impact crater Dantu. Icarus. https://doi.org/10.1016/j.icarus.2017.07.019

Stephan K., Jaumann R., Zambon F., Carrozzo F. G., Wagner R., Longobardo A., Palomba E., De Sanctis M. C., Tosi F., Ammanito E., Combe J.-P., Mc Fadden L.
A., Krohn K., Schulzeck F., derVon Gathen I., Williams D., Scully J., Schmedemann N., Neesemann A., Roatsch T., Matz K.-D., Preusker F., Raymond C. A., and Russell C. T. 2017c. Ceres' craters-Relationships between surface composition and geology. Icarus. https://doi.org/10.1016/j. icarus.2017.10.013

Wagner R. J., Schmedemann N., Stephan K., Jaumann R., Neesemann A., Preusker F., Kersten E., Roatsch T., Hiesinger H., Williams D. A., Yingst R. A., Crown D. A., Mest S. C., Raymond C. A., and Russell C. T. 2017. Stratigraphy and surface ages of Dwarf Planet (1) Ceres: Results from geologic and topographic mapping in Survey, HAMO and LAMO data of the Dawn Framing Camera Images: AGU Fall Meeting Abstracts. Volume 43.

Wieczorek M. A. and Zuber M. T. 2001. The composition and origin of the lunar crust: Constraints from central peaks and crustal thickness modeling. Geophysical Research Letters 28:4023-4026.

Williams D. A., Kneissl T., Neesemann A., Mest S. C., Palomba E., Platz T., Nathues A., Longobardo A., Scully J. E. C., Ermakov A., Jaumann R., Buczkowski D. L., Schäfer M., Thangjam G., Pieters C. M., Roatsch T., Preusker F., Marchi S., Schmedemann N., Hiesinger H., Frigeri A., Raymond C. A., and Russell C. T. 2017. The geology of Kerwan quadrangle of dwarf planet Ceres: Investigating Ceres' oldest, largest impact basin. Icarus. https://doi.org/10.1016/j.icarus.2017.08.015 